\title{
Los castros del oeste de la Meseta
}

\author{
The Western Meseta hillforts
}

\begin{abstract}
Ángel Esparza Arroyo
Departamento de Prehistoria, Historia Antigua y Arqueología. Universidad de Salamanca esparza@usal.es
\end{abstract}

Recibido: 15-11-2010

Aceptado: 11-03-2011

\begin{abstract}
RESUMEN
Los poblados fortificados del sector occidental de la Submeseta Norte tienen sus raíces en el grupo del Soto de Medinilla, a comienzos del primer milenio a.C. Partiendo de la delimitación habitualmente aceptada del solar donde se erigieron los castros, se pasa revista a los distintos grupos identificados en el paisaje: los primeros castros abulenses, salmantinos, del occidente zamorano y de los Montes de León. Siendo casi desconocidas en esta época (ca. 900-400 a.C.) las manifestaciones funerarias o la organización interna de los poblados, se presta especial atención a otros indicadores de cambio, como son las nuevas formas de ocupación y explotación del territorio y la cultura material. Este tipo de hábitat, poco jerarquizado, de economía autosuficiente y fuertemente vinculado al territorio circundante, conocerá un largo desarrollo durante la Edad del Hierro, llegando muchos de ellos hasta la romanización.
\end{abstract}

Palabras clave: Primera Edad del Hierro. Meseta occidental. Arquitectura defensiva. Patrones de asentamiento. Castros. Ritual funerario.

\begin{abstract}
The origin of the fortified villages in the Western part of the Northern Plateau lies in the 'Soto de Medinilla' cultural group at the beginning of the last millennium B.C. This paper analyzes the area where most of the hillforts are located, making an assessment of the different groups identified in its landscape: the first hillforts of Ávila and Salamanca provinces, and those from Western Zamora and the León Mountains. As the funerary record and the internal organization of the sites are almost unknown for this period (c. 900-400 B.C.), the paper focuses on other signs of social change, such as the new forms of occupying and exploiting the territory, and the material culture. This kind of human settlement, with little evidence of social hierarchy, self-reliant economy and strong links with the surrounding territory, will last during all the Iron Age, many of the sites being inhabited until the Romanization of the region.
\end{abstract}

KeY words: Early Iron Age. Western Meseta. Defensive architecture. Settlement patterns. Hillforts. Funerary ritual.

Sumario 1. Introducción. 2. La zona estudiada. 3. Un repaso a la información disponible. 4. Elementos para un análisis de conjunto. 5. La aparición del fenómeno castreño, un fenómeno controvertido. 


\section{Introducción}

No está de más iniciar esta introducción revisando el propio concepto de castro, cuya definición ha ido modificándose a medida que se introducían nuevas perspectivas teóricas, que tal vez no sean contradictorias, sino más bien complementarias.

Así, castro se ha entendido tradicionalmente como una realidad física, un poblado asentado en una elevación y protegido por defensas artificiales consistentes en una o varias murallas, fosos, etc. Ahora, a esta acepción de altura fortificada se le añade también un contenido socioeconómico: Almagro-Gorbea (1994: 15) se refiere a la existencia en su interior de varias viviendas de tipo familiar, así como al control de un territorio por parte del grupo residente, cuya organización social es poco compleja y jerarquizada. $\mathrm{Y}$ en los últimos años se insiste además en una faceta simbólica, al considerarlo también como monumento, pues el castro es la expresión visual de una comunidad y la afirmación de sus derechos sobre el territorio circundante. De esta forma, lo que se consideraba "arquitectura militar" vendría a ser de índole cuasi jurídica, pues como apuntan Burillo y Ortega (1999: 128) la muralla expresa materialmente la apropiación del territorio que la comunidad local reclama en exclusiva. Y en un sentido análogo, los investigadores del proyecto de Las Médulas (Fernández-Posse et al. 1994: 201; Orejas 1996: 86-88 y 100101) consideran las defensas como una forma de delimitación del espacio comunitario, y la construcción de las mismas, como un acto en el que se materializa la cohesión social, sin olvidar que los poblados adquieren una dimensión monumental en el paisaje, sirviendo como referencia ante propios y extraños.

Terminamos, pues, insistiendo en la riqueza de matices que contiene el término castro. Independientemente del valor defensivo ante hipotéticas amenazas (cuyo carácter, exterior o interno, habría que concretar en cada momento histórico), deberá retenerse el importante papel que en la estructuración del sistema sociocultural desempeñan los elementos colectivos de cierre: marcando de forma drástica la separación intramuros/ extramuros, definen el más importante espacio de las relaciones persona- les y comunitarias, y configuran en definitiva la sede de la integración social.

Clarificado el concepto de castro, debe precisarse también lo que se entiende aquí por castros del Oeste de la Meseta. Por razones didácticas, en el planteamiento de este libro se ha partido de una contraposición entre 'castros occidentales' y 'poblados del grupo Soto', pero la engañosa claridad de este punto de partida debe ser matizada de inmediato, porque su justificación es discutible, salvo que se esgrima $-\mathrm{y}$ no es poco- la conveniencia investigadora o docente. Ya la propia terminología empleada, tan equívoca, nos deja ver lo discutible de este reparto: se contraponen unos poblados fortificados y otros poblados que, al parecer, no lo son; además, no consta la atribución cultural de los primeros, mientras que de los últimos se señala explícitamente su pertenencia al grupo del Soto de Medinilla.

Honestamente deberíamos reconocer que lo que hay son dos situaciones bien diferentes derivadas en última instancia de la cobertera vegetal y del tipo de aprovechamiento económico actual, o lo que es lo mismo, dos niveles en el estado actual de nuestro conocimiento: yacimientos muy mal conocidos en el oeste, frente a los de las zonas centrales, de los que tenemos algo más de información. En efecto, si se miran bien las cosas, la realidad es más compleja, y los contrastes no son tan nítidos: advertimos, en primer lugar, que cada vez se encuentran más indicios de fortificación en poblados del Soto; al mismo tiempo, en los sectores occidentales empiezan a aparecer poblados coetáneos de los castros, pero no fortificados; sobre todo, debemos insistir en que muchos castros, zamoranos por ejemplo, revelan poco a poco que son yacimientos del grupo Soto, y algo similar parece ocurrir con los de los Montes de León y con los salmantinos, o los que empiezan a descubrirse en la Montaña palentina. Como luego veremos, hay razones para sostener - al menos como hipótesis de trabajo- que los castros del occidente formaron parte del grupo del Soto de Medinilla. No nos referimos, por supuesto, a la totalidad de los castros, puesto que entre ellos deben hacerse distinciones cronológicas: si algunos surgieron en los primeros momentos del desarrollo del grupo, otros son de cronología algo más avanzada, y un tercer grupo pertenece sin ninguna 
duda a tiempos bastante más tardíos que el Soto. Da la impresión de que, en los últimos siglos antes del cambio de Era, serán levantados los castros de las zonas más montañosas — La Corona de Corporales, en la Sierra de la Cabrera, es un ejemplo seguro (Fernández-Posse y SánchezPalencia 1988)_, tal vez por los mecanismos sociales con los que este tipo de poblamiento se relaciona: se ha sugerido que la estructura socioeconómica castreña obligaba a dar salida al "excedente demográfico" recurriendo a la formación de nuevos poblados análogos, y ésto, andando el tiempo, habría llevado necesariamente a colonizar los espacios más montañosos desocupados en los siglos anteriores.

Con todo, y en aras de una más fácil comprensión de los datos arqueológicos, tan fragmentarios y discutibles, daremos por bueno hechas estas advertencias - el planteamiento inicial, pasando a ocuparnos, como un conjunto, de los castros de las zonas más occidentales de la submeseta norte. Eso sí, determinados detalles nos llevan a distinguir en el bloque varios subconjuntos, que denominaremos de la siguiente forma: a) primeros castros abulenses; b) castros salmantinos; c) castros del occidente zamorano; y d) castros de los Montes de León. Hay que aclarar, por supuesto, que esta terminología que alude a los actuales límites provinciales - existentes sólo desde 1833 - pretende únicamente facilitar el primer acercamiento a los problemas. En realidad, cabría derribar la barrera entre los dos primeros, o también entre los del suroeste de Zamora y los salmantinos, etc., pero lo cierto es que, por razones diversas (organización institucional y financiación especialmente), las investigaciones se han adaptado en buena medida a los marcos administrativos, y la bibliografía lo refleja nítidamente, acentuándose los matices diferenciales. En cuanto al orden de nuestra exposición, responde a la propia historia de la investigación, pues aquellos que se citan en primer lugar fueron estudiados con anterioridad a los zamoranos y leoneses. Y un ultimo matiz: los límites cronológicos establecidos con buen criterio para la primera parte de este libro, esto es, 900-400 a.C., enmarcan sin duda una parte muy importante de lo que llamaríamos mundo castreño, pero no todo: si a partir de la cómoda fecha del 400 se advierten en otras áreas los trascendentales cambios que serán abordados en la segunda parte del libro, en las zonas que aquí estudiaremos, acaso por su propia posición en relación con procesos de alcance peninsular, tales cambios se observan con dificultad, o con gran retraso, por lo que podría hablarse de una persistencia de los castros del oeste hasta momentos muy tardíos, incluso hasta la profunda reorganización territorial impuesta por los romanos.

\section{La zona estudiada}

Concretemos el ámbito territorial estudiado en este capítulo, que podría definirse, en primer lugar, de forma más bien negativa: se trata de unas comarcas en las que faltan las llanuras sedimentarias que constituyen el solar más característico del grupo del Soto de Medinilla. Con mayor precisión diremos que abarca las zonas más occidentales de la Submeseta Norte, inmediatas a la orla montañosa que encierra la cuenca terciaria del Duero. (Fig. 1). Estamos, pues, en un arco que incluye desde el piedemonte y las Montañas Galaico-Durienses que ocupan parte de León y de Zamora hasta las sierras de Francia, Béjar, Gredos, La Paramera y de Ávila. Entre medias, unas comarcas zamoranas y salmantinas (Sanabria, Aliste, Sayago, Tierra de Ledesma, El Abadengo, etc.) que no son estrictamente montañosas, pero se integran en este conjunto por sus características geomorfológicas y ecológicas: se trata de un vasto grupo de penillanuras - son los residuos de un viejísimo Macizo Hespérico desgastado por la erosión-, pizarrosas unas y graníticas las otras, de relieve más o menos pronunciado y que se hallan a sotavento de las importantes barreras que para los frentes atlánticos suponen las sierras del Norte de Portugal. De ahí el que, con las lógicas diferencias debidas a la altitud, puedan considerarse un ámbito comparable a los otros más montuosos. En cambio, se ha dejado fuera la Submeseta meridional, más concretamente, Extremadura, en la que algunos de los castros, de Ávila por ejemplo, encontrarán afinidades, de la misma forma que otros las tienen en el Noroeste. La búsqueda de un "marco natural" que facilite el análisis se ha impuesto, y así, desde el punto de vista de la flora, vegetación y biogeografía, la separación es bien clara. 


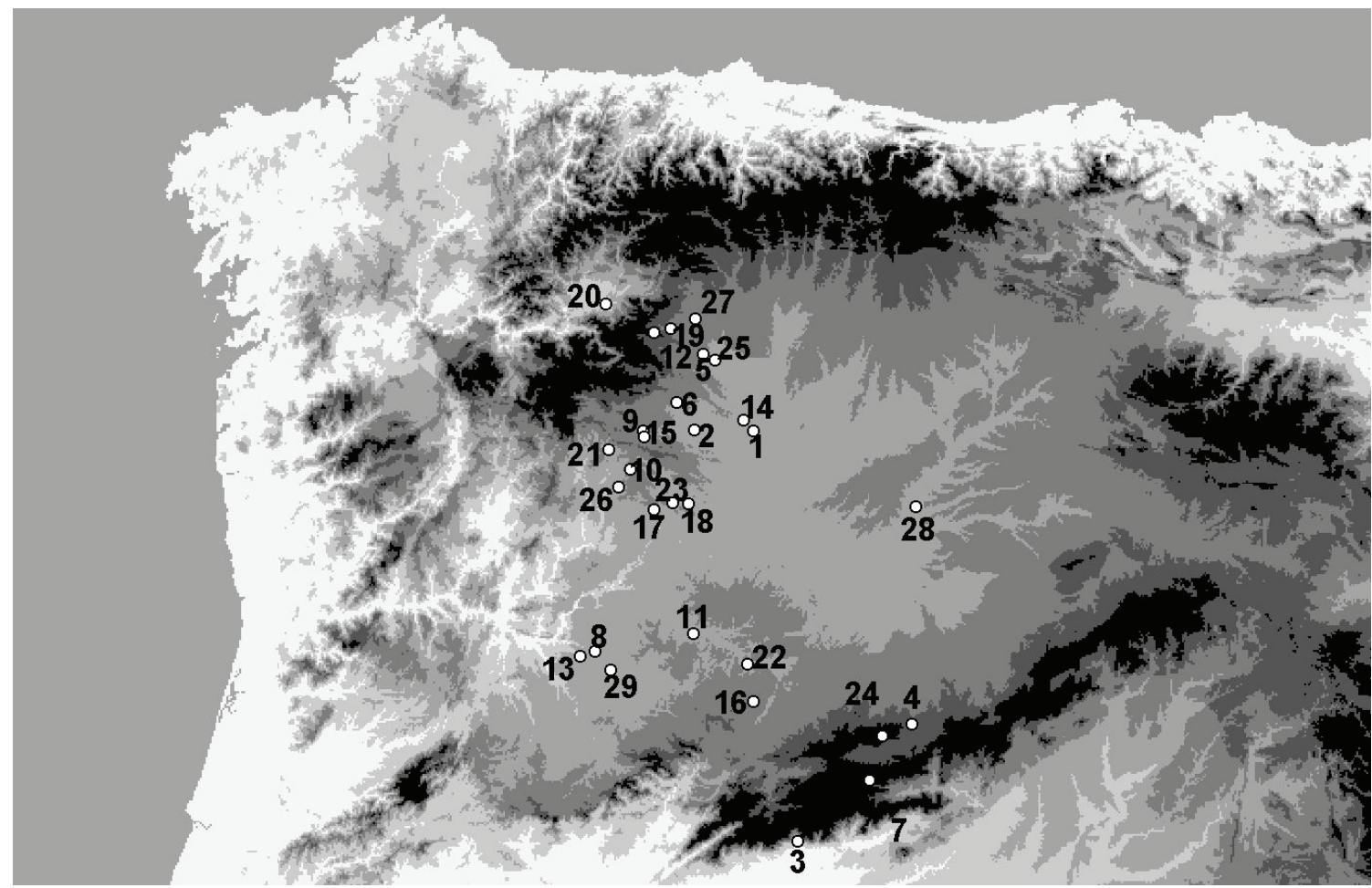

Figura 1.- Principales yacimientos que se mencionan en el capítulo. - 1: Benavente; 2: Camarzana de Tera (El Castro); 3: Candeleda (Las Guijas); 4: Cardeñosa (Las Cogotas); 5: Castrotierra de la Valduerna (El Castro); 6: Cubo de Benavente (La Armena); 7: El Tejado (El Berrueco); 8: Encinasola de los Comendadores (Picón de la Mora); 9: Fresno de la Carballeda (El Castro); 10: Gallegos del Campo (La Mazada); 11: Ledesma (Plaza de San Martín); 12: Lucillo (La Corona); 13: Lumbrales (Las Merchanas); 14: Manganeses de la Polvorosa (Corona /Pesadero); 15: Manzanal de Abajo (El Castillo); 16: Martínamor (San Pelayo); 17: Moveros (Cerro de la Luz); 18: Muga de Alba (Las Tapias); 19: Pedredo (El Castro); 20: Ponferrada (El Castillo); 21: Riomanzanas (El Castro); 22: Salamanca (San Vicente); 23: Samir de los Caños (El Villar); 24: Sanchorreja (Los Castillejos); 25: Santiago de la Valduerna (Sacaojos); 26: Sejas de Aliste (El Cerco); 27: Sopeña (El Castro); 28:Valladolid (El Soto de Medinilla); 29: Yecla de Yeltes (Yecla la Vieja).

De contar con una información más completa, acaso se pudieran integrar en este mismo conjunto otros espacios colindantes, como los de las montañas cantábricas que discurren por el norte de León, donde Gutiérrez González (1986-87) catalogara sesenta y tantos castros, pero en los que los materiales hallados -alguna cerámica, fíbulas, broches tipo Majúa, etc.- solamente permiten señalar una ocupación en la Plena Edad del Hierro, relacionable con los poblados de las llanuras más al sur; y también podrían incluirse la montaña de Palencia, y otras zonas serranas de Ávila en las que trabajosamente se van descubriendo yacimientos de carácter castreño. Sin embargo, por ser todavía insuficiente su conocimiento, nos resistimos a incorporarlos prematuramente a una síntesis que se ceñirá, según lo dicho, al sector más occidental de la región.

El relieve accidentado sería, pues, la primera característica de estas zonas que comentamos; la segunda es la pobreza de sus suelos. Ciertamente, las condiciones edáficas de hoy no deben ser extrapoladas al pasado, pero teniendo en cuenta el tipo de sustrato geológico y la climatología inferida para los últimos tiempos prehistóricos, no es injustificado suponer en estas zonas un importante grado de correspondencia entre los suelos de la época y los actuales. Se trata de terrenos de los tipos denominados 'tierras pardas' y 'suelos pardos', de poca profundidad, ácidos por haberse desarrollado sobre rocas silíceas o graníticas, y con poco fósforo y materia orgánica, todo lo 
cual supone severas limitaciones para la agricultura. Es verdad que las prácticas agrícolas tradicionales han conseguido, durante siglos, obtener en los retazos más favorables algunas cosechas de cereales de secano, pero en todas estas comarcas, extensiones muy importantes del terreno presentan más bien una aptitud como pastizales, o incluso meramente forestales, y es esta 'vocación', como la denominan los edafólogos, la que debe tenerse presente.

Respecto a las condiciones ambientales reinantes en la zona de estudio en el primer milenio antes de Cristo, debemos partir en principio de los resultados establecidos en otras zonas del continente europeo, donde el Holoceno ha sido subdividido desde el punto de vista climático en varios periodos, de los que nos interesa mencionar los últimos: en una fecha en torno al 800 a.C. se habría producido la transición entre las periodos denominados Subboreal y Subatlántico, de forma que nuestros castros habrían desarrollado su existencia bajo las condiciones del Subatlántico, más templadas y húmedas que las de la etapa anterior. Los ensayos de recomposición de la dinámica atmosférica efectuados entre otros por Magny (1982) o por Ruddiman y MacIntyre (1981) ayudan a establecer de manera aproximada cuales pudieron ser aquellas condiciones, y algún análisis sedimentológico, como el que se hizo en el poblado de La Aldehuela, en las afueras de la capital zamorana (Jordá Pardo 1994: 227-228), vendría a corroborar que el clima del primer milenio a.C. no era muy distinto del actual, si acaso más lluvioso. Pero sobre todo es la investigación botánica la que ha permitido efectuar reconstrucciones paleoambientales cada vez más precisas.

En efecto, atendiendo a criterios florísticos y ecológicos, los especialistas han establecido una serie de grandes regiones biogeográficas, divididas en provincias y sectores, siendo las montañas que constituyen los límites occidentales y septentrionales de nuestra submeseta la línea de separación entre la Región EuroSiberiana y la Región Mediterránea. Dentro de ésta, caracterizada por la existencia de un periodo de aridez estival, y más precisamente dentro de la Provincia Carpetano-Ibérico-Leonesa, quedarían incluidos todos los espacios que nos interesan, en concreto en los denominados
Sector Orensano-Sanabrés, Sector Salmantino y el Sector Bejarano-Gredense. Insistamos en la exclusión de la Alta Extremadura, que pertenece a otra Provincia biogeográfica.

Las investigaciones fitosociológicas hacen posible recomponer la distribución de la vegetación de estos sectores durante el Holoceno, aunque la verificación de tales propuestas, que debe hacerse a partir de análisis paleobotánicos, especialmente polínicos, está todavía incompleta. Con todo, la pertenencia a la Región Mediterránea tiene consecuencias fácilmente perceptibles: el período de temperaturas más elevadas del año coincide con una reducción en las precipitaciones que no se ve compensada por la evapotranspiración potencial, lo que supone un importante déficit hídrico que repercute notablemente en la vegetación. La integración de los datos polínicos, de los relativos a esos fenómenos más generales de circulación ciclónica, fitosociología, etc., permiten obtener algunas conclusiones válidas para el periodo Subatlántico, al menos en sus aspectos generales, (vid. por ejemplo Ramil-Rego 1993; Ramil-Rego et al. 1996; Muñoz-Sobrino et al. 1996).

Lamentablemente, no abunda información para las comarcas de Ávila o Salamanca hay varias tesis doctorales de la Universidad de Alcalá, inéditas, con muchos perfiles polínicos para estas zonas-, hallándose actualmente en curso de realización un estudio paleobotánico de conjunto de toda la zona zamorana. Pero un cuadro bastante completo se está obteniendo muy recientemente en el abulense Valle Amblés (Blanco 2008; López-Sáez et al. 2008 y 2009). De esta forma, lo que mejor se conoce es la zona de las montañas zamoranoleonesas (Ramil-Rego et al. 1998), donde podemos partir del "óptimo climático", momento de máxima recuperación tras la deglaciación: en la zona de cumbres del Macizo GalaicoDuriense se habrían dado diversos matorrales y retazos boscosos de pinos y abedules; en zonas de menor altitud, dominaba el roble caducifolio, acompañado por avellanos, olmos, fresnos, castaños, etc., anotándose la presencia de encinas y acebuches en los sectores más meridionales. Pero en el Subatlántico, marco cronológico de nuestros castros, se habría venido registrando una fuerte antropización del 
paisaje, en relación con la agricultura. Las perturbaciones detectadas —disminución del polen arbóreo, aumento del polen de cereales y de determinadas herbáceas - parecen debidas tanto a la introducción y extensión de las plantas cultivadas como a la realización de prácticas deforestadoras, que habrían ido configurando lo que se ha denominado estepa cultural, en la que una cobertera arbórea en continua regresión va siendo sustituida por formaciones arbustivas $\mathrm{y}$ herbáceas.

A tenor de lo que poco que se ha publicado de esos perfiles antes citados (Andrade Olalla et al. 1996), en las zonas de Ávila-Salamanca, donde hubo también pinos en zonas más altas y dominio del robledal y sobre todo del encinar en zonas más bajas, se comprueba también ese proceso gradual de antropización del medio .

Habida cuenta de las características biogeográficas y de la relación observada en otras partes entre los datos paleobotánicos y los recientes, se podría concluir aludiendo a las condiciones relativamente duras que hubieron de afrontar en toda nuestra zona de estudio las gentes de la primera mitad del último milenio a.C. En relación con las peculiaridades edáficas y topográficas, con un clima caracterizado por inviernos largos y crudos y por la aridez estival, las comunidades asentadas en todas estas zonas han debido de practicar una economía agropecuaria bien ajustada al medio, lo que equivale a decir un aprovechamiento inteligente del limitado abanico de recursos complementarios disponibles - el terrazgo agrícola más bien escaso, los linares, el monte, los prados, los frutales, etc.al que apuntan también los datos arqueológicos: en definitiva, una economía tendente a la autosuficiencia, y casi de mera subsistencia, es decir, no muy holgada. Desde luego, no debemos caer en la consideración de tales comunidades como meros entes adaptativos, sujetos pacientes de las limitadas posibilidades del medio, pero tampoco en una visión idealizada de unas sociedades tradicionales pretendidamente respetuosas con la naturaleza. Porque en su aprovechamiento del medio, sin duda muy condicionado por lo rudimentario de su tecnología, estas gentes intervinieron fuertemente sobre él, convirtiéndolo en un paisaje modelado en función de sus necesidades y pretensiones, $\mathrm{y}$, como ya se ha visto, muy diferente del natural: debido a las prácticas deforestadoras, realizadas mediante el hacha o el fuego, los bosques iban dejando paso a unas landas antrópicas, a unas extensiones de pobres matorrales que se van detectando en los análisis polínicos.

En los yacimientos que nos ocupan no abundan precisamente los estudios zooarqueológicos, de forma que apenas disponemos de datos de esta índole para aplicarlos a la reconstrucción paleoambiental. Pero los paisajes antes citados encajan con la fauna doméstica - vacuno, ovejas y cabras, caballos y cerdos - y sobre todo la silvestre cuyos huesos se han encontrado repetidamente, siendo destacable en este sentido la identificación del lobo y el zorro, del jabalí, del corzo y el rebeco, una cierta importancia del ciervo, e incluso la presencia del lince y el oso, que testimonian la existencia de medios que todavía no habían alcanzado los grados de alteración que conocemos en los últimos tiempos.

\section{Un repaso a la información disponible}

\subsection{La aparición de castros en la zona de Ávila}

Si nos interesamos por los castros de esta zona, es obligado mencionar en primer lugar el Cerro del Berrueco (Maluquer 1958a; Piñel 1976; Fabián 1986-87; Conde et al. 1996), en el límite de las provincias de Ávila y Salamanca, donde en fechas tempranas, todavía dentro del Bronce Final, pudo haber un poblado fortificado. Efectivamente, el poblado de Cancho Enamorado, establecido en los riscos más altos del cerro (Fig. 2), contaba ya, según Maluquer, con una muralla constituida por bloques de piedra que iban uniendo diversos canchales graníticos. Aunque algunos investigadores han vuelto a referirse a dicha estructura -que sería, eso sí, un muro poco organizado, sin paramentos - , su existencia ha sido cuestionada por Fabián. Desde luego, si hubo tal cierre, seguramente respondía a necesidades de control de los ganados, o bien a otras de carácter social y político, sin que admita parangón con las potentes fortificaciones que caracterizarán a los castros de la Edad del Hierro. Por eso, hemos de continuar nuestra presentación adentrándonos en esta Edad. 
No deja de sorprender el que en la misma zona donde se conocen importantísimos yacimientos de la Edad del Bronce -El Berrueco citado, Sanchorreja, Las Cogotas - y castros de la Segunda Edad del Hierro no menos importantes -Ulaca, La Mesa de Miranda y el propio de Las Cogotas - , sea escasa la información relativa al Hierro Antiguo, que se documenta casi exclusivamente en Sanchorreja, lo que ha dado pie a hablar de un "agujero negro" existente en la Primera Edad del Hierro del borde suroeste de la región (Ruiz Zapatero y Álvarez-Sanchís 1995: 231).

En realidad, algunos datos indican que en otros yacimientos pudo haber también una ocupación de este oscuro periodo. En El Berrueco (Fabián 1986-87; 2005; Conde et al. 1996), por ejemplo, parece haberse producido una modificación importante: aquel poblado del Bronce Final instalado en la cumbre del cerro, se abandona, y en cambio surge un nuevo núcleo en una zona más baja (Fig. 3). El nuevo poblado carece de fortificación, y además el sitio donde se asienta, llamado Las Paredejas o Santa Lucía, presenta pocas posibilidades defensivas. El nuevo poblado, que parece responder a otro tipo de preocupaciones, ha proporcionado cerámicas a mano con decoración a peine, también algunas a torno, tal vez ibéricas, y diversos objetos de bronce (fíbulas, braserillos, etc.) de tipo orientalizante. Estos materiales sugieren una cronología posible entre los siglos VIII y III a.C., pero centrada entre los siglos VII y IV a.C. (Fabián 2005). Como el yacimiento sólo se conoce por objetos de superficie, es difícil justificar el cambio de emplazamiento que allí se produjo. Únicamente podría hacerse constar la presencia de un fragmento cerámico de un vaso troncocónico con pintura amarilla y roja, que recuerda a otros frecuentes en los yacimientos del grupo Soto, sin que sea fácil extraer con-

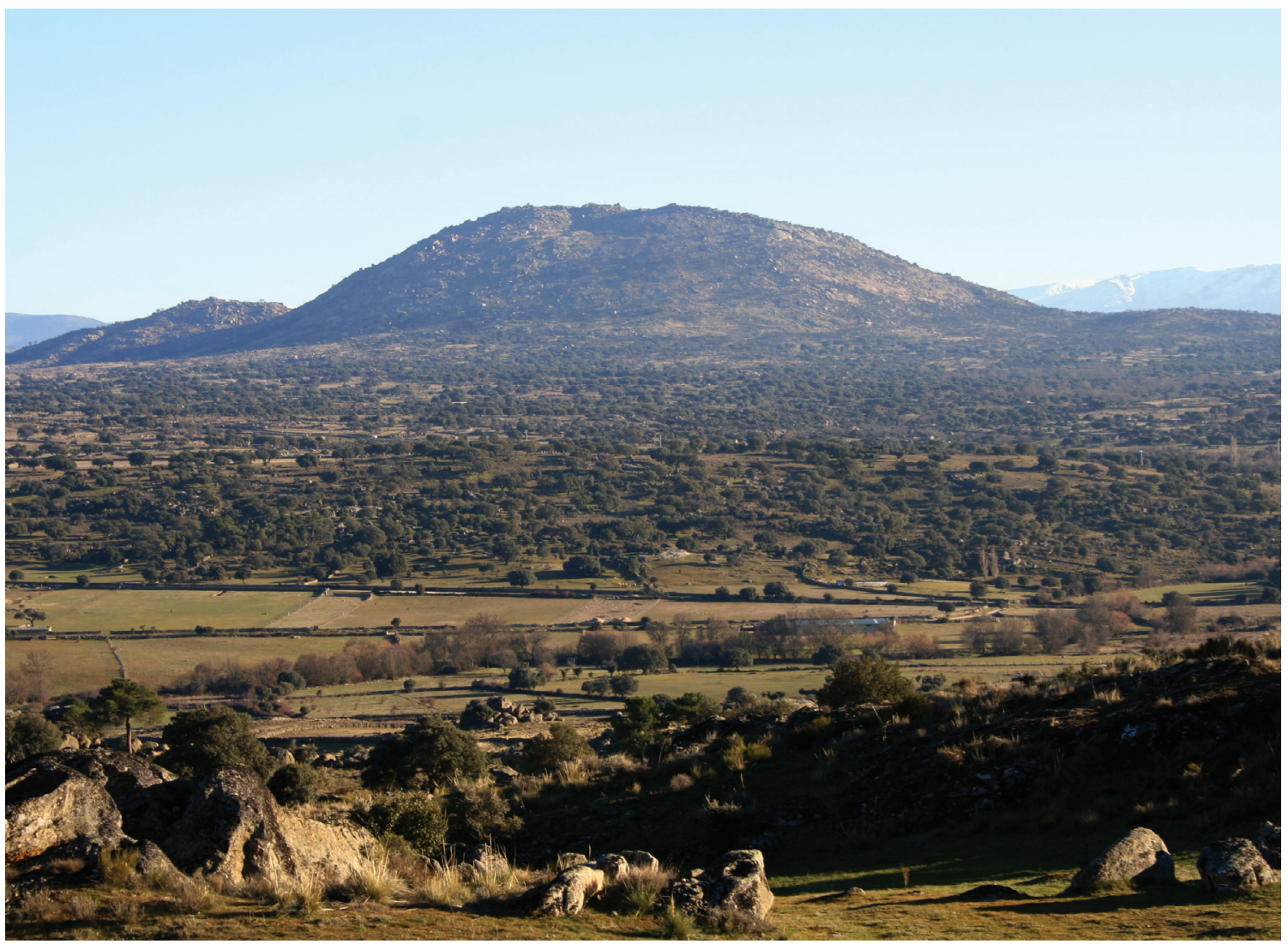

Figura 2.- El cerro de El Berrueco (Medinilla-El Tejado), desde el norte (foto de F. Fabián). 

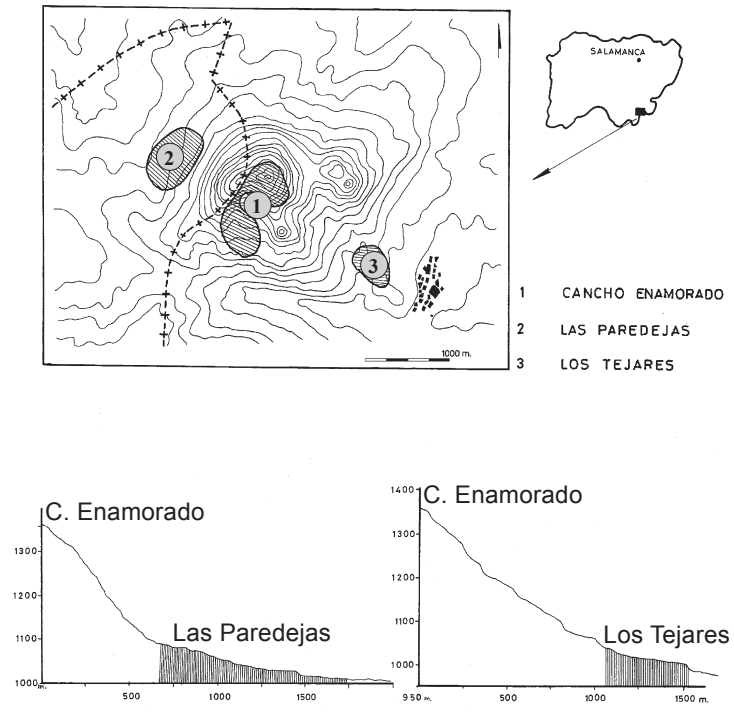

Figura 3.- Principales yacimientos del Cerro del Berrueco, mostrando el cambio de emplazamiento operado en la Edad del Hierro (según Fabián 1986-87).

clusión alguna, dado que estas cerámicas se hallan presentes también en Sanchorreja.

Otro yacimiento que suministra datos de interés es el castro de Las Cogotas. En él se han venido identificando con claridad dos momentos: inicialmente el sitio había sido ocupado a comienzos de la cultura de Cogotas I, posiblemente entre los siglos XV-XII a.C. (Delibes 1995: 69-70; Abarquero 1997 y 2005); mucho más tarde, a finales del siglo V o ya en el IV a.C., se construirán las fortificaciones que darán cobijo a un importante poblado de la Segunda Edad del Hierro (Ruiz Zapatero y Álvarez-Sanchís 1995; Ruiz Entrecanales 2005). Pero recientemente Álvarez-Sanchís (1999: 74-75) ha sugerido que algo antes, en los siglos VI-V a.C., había ya una presencia humana importante en el sitio: algunos fragmentos cerámicos con decoración de peces incisos y botones de bronce incrustados, y también algunos objetos de bronce de estilo orientalizante, dan pie a esas sospechas. Sospechas que un estudio reciente ha confirmado al revisar estos materiales y situarlos en el Hierro Antiguo (Blanco González 2010b). Horizonte que van deparando algunos asentamientos nuevos en llano como Guaya, en Berrocalejo de Aragona (Misiego et al. 2005).
Aunque se halla al sur de la sierra de Gredos, podría mencionarse, para reforzar la misma tendencia que se va apuntando, los yacimientos de Candeleda (Fernández Gómez 1986, 1997 y 2008): el importante castro de El Raso no surgirá hasta el siglo III a.C., pero en la necrópolis de Las Guijas, algunas tumbas, en especial la denominada orientalizante por su ajuar que incluía diadema de oro, asador y braserillo de manos, parecen apuntar también al Primer Hierro, dando pie a sospechar la existencia de un poblado anterior al Raso, que parece haberse confirmado, y que tampoco contaría con defensas.

Los poblados que se han citado, a pesar de sus diferencias en cuanto a emplazamiento, vendrían a coincidir en la ausencia de fortificaciones. Parecería, pues, que los poblados con importante aparato defensivo, los castros en definitiva, surgieron en esta zona en un momento posterior al que nos ocupa (González-Tablas 2009). Pero el caso de Sanchorreja, ciertamente amurallado en el Primer Hierro, nos sitúa ante un proceso diferente. Detengámonos, pues, en una presentación resumida de este yacimiento excepcional.

El poblado de Los Castillejos, en Sanchorreja, fue excavado en los años treinta por Cabré, Navascués y Camps, pero el estudio de los materiales y los diarios de las campañas sería realizado mucho más tarde por Maluquer (1958b), no sin problemas, derivados de la falta de algunos documentos, o de la propia forma de excavar de aquella época. En los años ochenta, González-Tablas ha efectuado nuevas excavaciones, cuyo estudio (González-Tablas 1983, 1986-87, 1989, 1990, 1991 у 2005; González-Tablas y Domínguez Calvo 1995 y 2002; González-Tablas et al. 1986 y 1991-92) ha permitido confirmar algunos aspectos, pero también replantear otros.

Se trata de una imponente elevación (Fig. 4), casi un monte isla, con grandes canchales graníticos, que descuella claramente sobre grandes extensiones de terreno de orientación eminentemente ganadera. La existencia de manantiales facilitaría la vida en el poblado, que quedaría de todas formas sometida a fuertes contrastes térmicos — se halla a más de 1500 $\mathrm{m}$ de altitud - y marcada por la dificultad del acceso, pues descuella más de $150 \mathrm{~m}$ sobre la 
base. El poblado, en su estado final, presentará largos lienzos de muralla que describen tres recintos (Fig. 5). Al exterior, en la zona más oriental, se han encontrado una serie de estructuras que contenían notables objetos metálicos $\mathrm{y}$ que han sido interpretadas en relación con ritos de carácter funerario (González-Tablas 1990).

Tanto en las excavaciones antiguas como en las recientes parecen haberse documentado seis niveles. Excluyendo los más altos - niveles I y II-, afectados por procesos postdeposicionales, los más interesantes son los VI-V (denominados habitualmente "niveles inferiores") y los niveles IV-y III, o "superiores", que remiten respectivamente al Bronce Final y a la Primera Edad del Hierro. Sin embargo, mientras no se publiquen los resultados de las campañas recientes, resulta difícil de valorar algunos aspectos de la estratigrafía, como la interpretación del nivel VI, tradicionalmente considerado de Cogotas I, pero sobre el que ahora hay alguna reserva (González Tablas 1989: 118).

De este modo, cabe arrancar de una primera fase en la que el yacimiento fue ocupado solo en una pequeña extensión, concretamente en la parte más elevada- por gentes portadoras de la cultura de Cogotas I, que parecen ha-
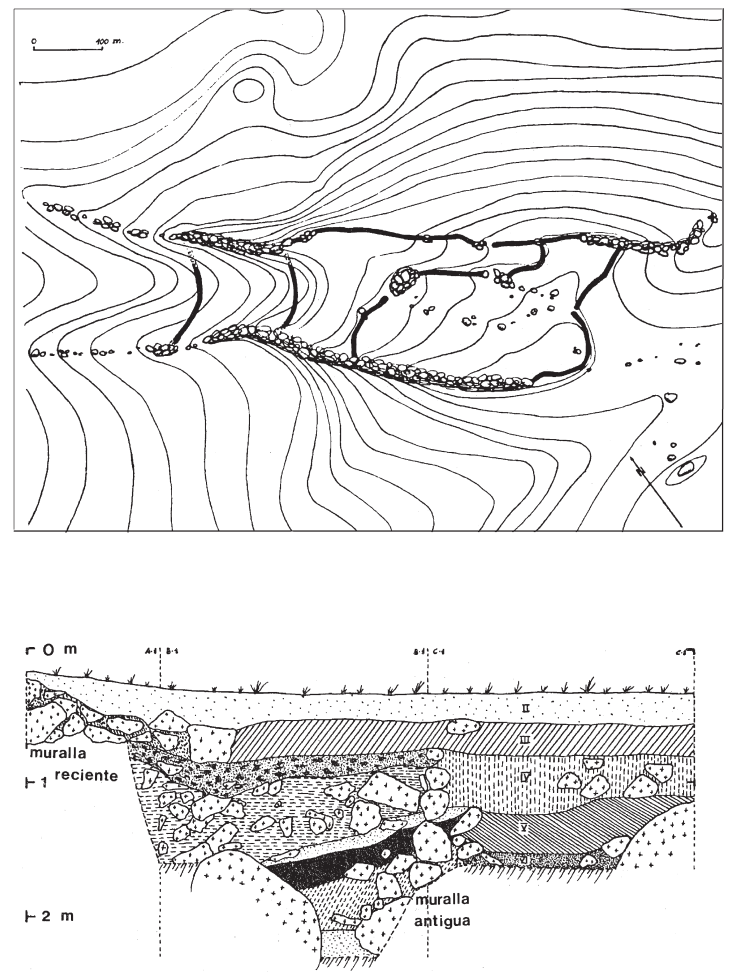

Figura 5.- a) Plano del castro de Los Castillejos, en Sanchorreja. b) corte estratigráfico en el que se observan las dos murallas existentes (según GonzálezTablas et al. 1986).

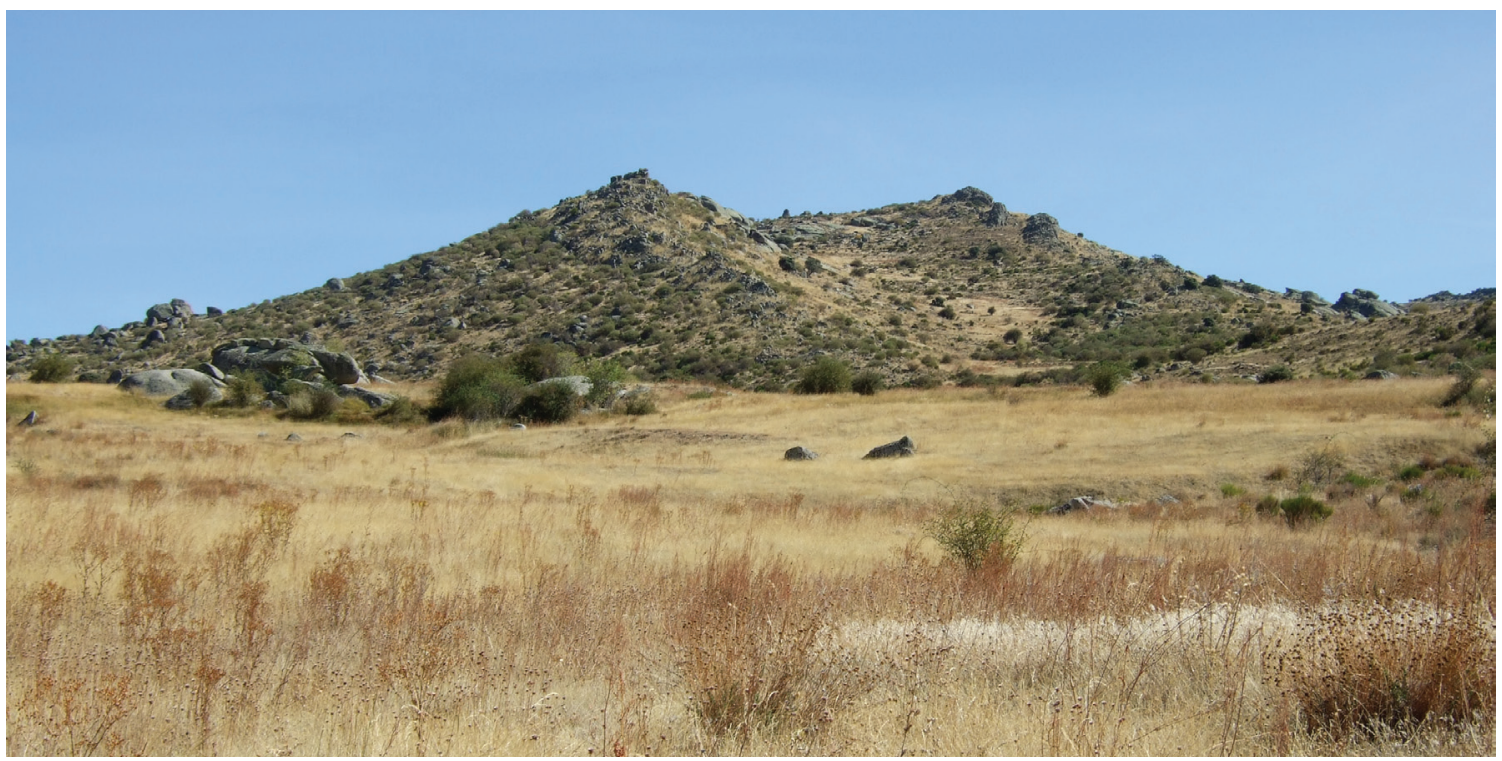

Figura 4.- Castro de Los Castillejos de Sanchorreja (Ávila) (foto de A. Blanco). 
ber levantado una muralla rudimentaria, como la que se mencionó en Cancho Enamorado u otras de la misma atribución cultural, y datable al parecer en el siglo $\mathrm{X}$ a.C. Las características nos hacen pensar, más que en una fortificación, en esos cercados, poco elaborados pero de imponentes dimensiones, que se van documentando desde los tiempos formativos de Cogotas I.

El nivel V, considerado segundo momento de la ocupación Cogotas I, se extiende ya por todo el poblado, y proporciona abundantes cerámicas con boquique y excisión, y lo que es más importante, algún fragmento cerámico con temas geométricos pintados en rojo carmín, relacionable con las de El Carambolo, así como otro con incrustaciones de botones de bronce o cobre. Por sus relaciones con el mundo meridional, esas cerámicas con pintura monócroma han sido llevadas al siglo VII a.C., lo que serviría para datar también el final de la ocupación Cogotas I. Por encima aparecen ya los niveles superiores, comenzando en el nivel IV la cerámica con decoración incisa a peine, donde hay también cerámica pintada con posterioridad a la cocción (González-Tablas y Domínguez 1995: 190). Sin un contraste marcado se pasa al nivel III, también con cerámica peinada y pintadas bícromas, así como algunas torneadas de pasta amarillenta y con decoración pintada en rojo vinoso, que parecen hechas en lejanos ambientes ibéricos. Es precisamente en el comienzo de este nivel III donde se levantó la muralla, hecha de mampostería en seco. Sus grandes dimensiones - se encierran más de 25 has con un muro que llega a tener unos $6 \mathrm{~m}$. de espesor-y la yuxtaposición de los recintos nos recuerdan lo que veremos en los grandes castros de Ávila correspondientes a la plenitud de la Edad del Hierro. Sin embargo, no se observa la notable técnica de las murallas de éstos, pues faltan los cuidados paramentos, o las torres y bastiones, o las defensas complementarias como fosos o barreras de piedras hincadas. Tampoco las entradas, reducidas aquí a meras interrupciones que incluso aprovechan los canchales graníticos, tienen nada que ver con las de complejos diseños de esos castros más tardíos.

La cronología de estos recintos amurallados, que Maluquer (1958b: 96) situaba poco después del 500 a.C., ha sido envejecida por GonzálezTablas, quien la lleva a fechas de la segunda

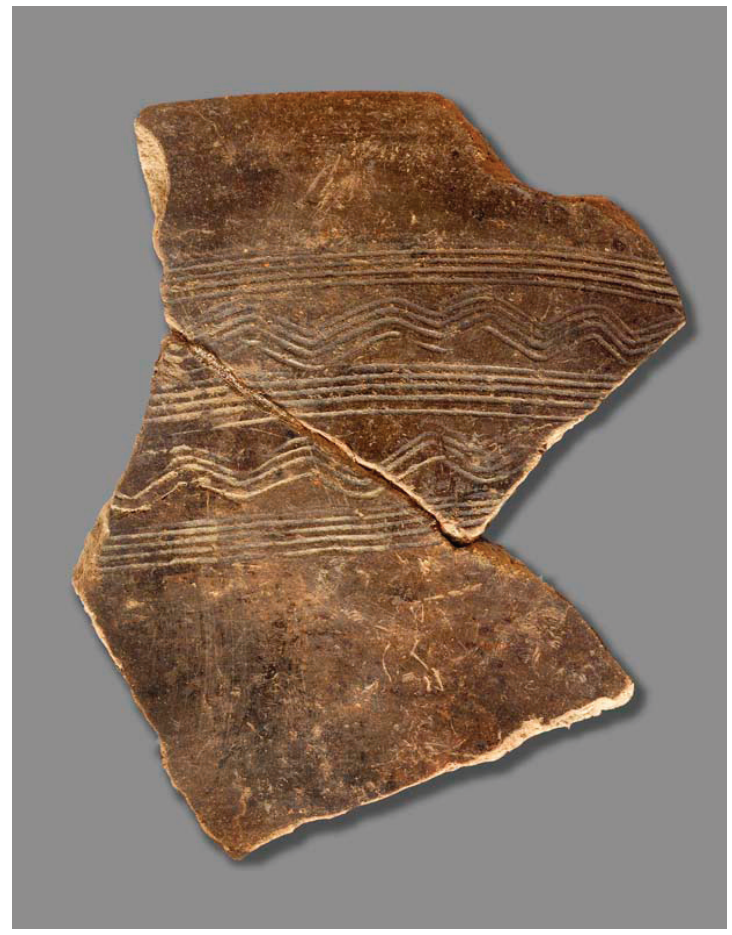

Figura 6.- Fragmento de cerámica con decoración a peine del castro de Sanchorreja (foto de Mario Torquemada, Museo Arqueológico Regional, Madrid).

mitad del siglo VI a.C. (1986-87: 52), e incluso a la primera (1990:73). En cuanto al final, no hay en el poblado indicios de destrucción, por lo que se supone que debió de ser abandonado aproximadamente hacia el 400 a.C. o muy poco después, dado que no se han hallado materiales más recientes.

De los materiales publicados cabe glosar la existencia de abundante cerámica a mano con decoración a peine (Fig. 6). Se trata especialmente de cuencos, en los que la decoración, trazada con un peine muy fino, se dispone en el interior del vaso, y también de pequeñas ollas con decoración peinada en el exterior organizada en frisos horizontales, delimitados por líneas de peine y rellenos de motivos geométricos sencillos (zigzag, ángulos, líneas sinuosas). Recordemos también los vasos con decoración pintada bícroma, en rojo y blanco, o en rojo y amarillo. Abunda, como es lógico, la cerámica común, en la que se han ido advirtiendo puntos de contacto con las del Soto.

Los objetos metálicos hallados son notables, aunque desconocemos la posición es- 
tratigráfica de muchos de ellos, especialmente los procedentes de labores clandestinas (González-Tablas et al. 1991-92). Destacamos la presencia de cuchillos de hierro y fíbulas de doble resorte broncíneas, pero también de otros objetos de bronce como los recipientes rituales denominados braserillos (Fig. 7) o los broches de cinturón, incluyendo alguno de tipo tartésico. Se trata de objetos de fuerte carga simbóli$\mathrm{ca}$, vinculados, al menos en origen, al mundo Orientalizante, y que acabaron teniendo gran predicamento en los yacimientos meseteños del Primer Hierro. Ya se trate de productos importados o de manufacturas locales inspiradas en modelos foráneos -González-Tablas y Domínguez (1995:193) aluden a actividad metalúrgica, pues se han hallado moldes y crisoles_-, indican relaciones con el mediodía peninsular, y no es aventurado sospechar que el florecimiento del poblado se relacionó con su papel en un intercambio de bienes en el que se entretejían economía, jerarquía social y relaciones políticas.

Lamentablemente, apenas se han publicado datos relacionados con otras actividades, agrícolas, por ejemplo, que pueden suponerse a partir de los molinos de vaivén, naviformes, o de los cereales cuyo polen parece haber au- mentado en estos niveles superiores (GonzálezTablas 1983: 24). Y en cuanto a la ganadería, que cabría intuir basándose en el tipo de terrenos cercanos al poblado, parece haberse dado el paso de una ganadería de ovicápridos a otra de bóvidos y suidos, habiendo que mencionar también una cierta importancia de la caza.

El castro de Sanchorreja, con sus recintos amurallados, supone como hemos visto una excepción en su época. Ello nos obliga a preguntarnos finalmente por las posibles razones del amurallamiento. En consonancia con las corrientes interpretativas del momento, González Tablas sugirió inicialmente (Ibid.: 19) que se debía a la presencia en la Meseta de los primeros incineradores procedentes del Valle del Ebro o de la zona catalano-levantina. Después (1986-87: 55 y 1990: 73), ha preferido señalar la coincidencia de la murallas con la pujanza del yacimiento y con la expansión que Sanchorreja y su hipotético grupo cultural (en el que incluía yacimientos como el salmantino cerro de San Vicente) habrían realizado hacia el valle medio del Duero, expansión que habría provocado el final del Soto. Considerando la muralla en relación con el esplendor del yacimiento, Álvarez-Sanchís (1999: 77) señala que, más que un elemento estrictamente defen-

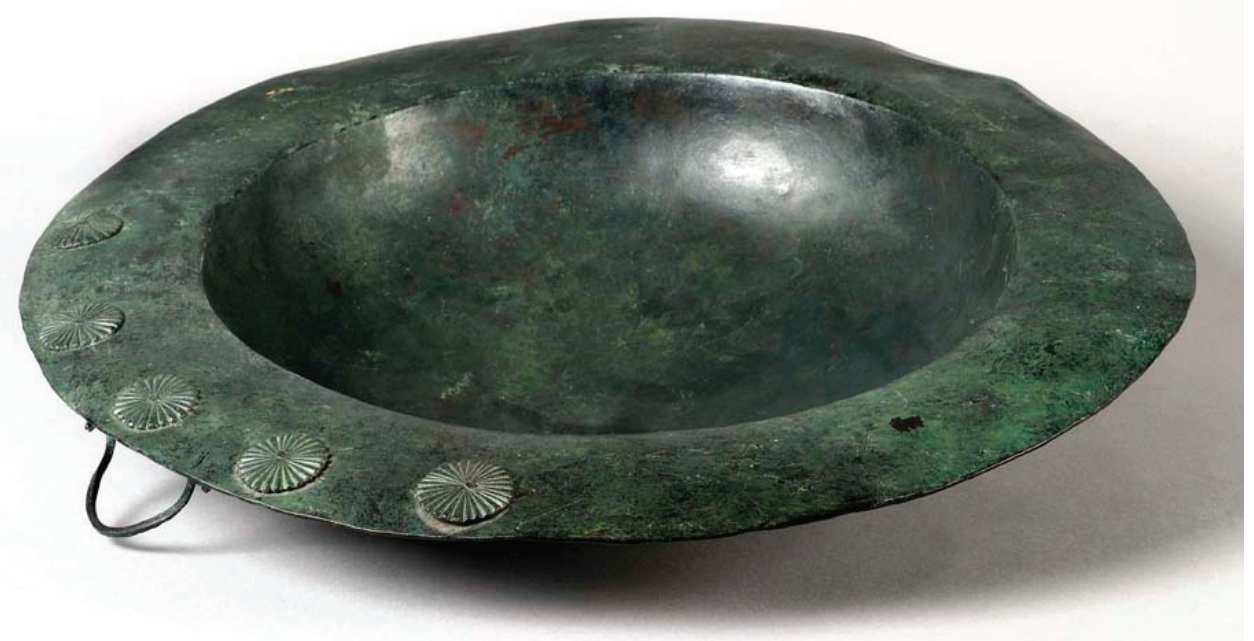

Figura 7.- Brasero ritual del castro de Sanchorreja (foto de Mario Torquemada, Museo Arqueológico Regional, Madrid). 
sivo, casi innecesario por lo difícil del acceso, la muralla debió de servir como un elemento estructurador del poblado y la comunidad que lo habitaba, bajo el control de una aristocracia local.

En cuanto al abandono del poblado, que no llegó a alcanzar la plenitud de la Edad del Hierro, el propio González-Tablas (1983: 27) apuntó que habría perdido su razón de ser, ya que en los nuevos tiempos se podrán elegir asentamientos en sitios menos escabrosos y con mayores recursos en sus cercanías, compensándose su relativa desventaja mediante una compleja arquitectura militar (id. 2009).

\subsection{Los castros de Salamanca}

En el área salmantina, donde los castros tendrán asimismo una gran importancia en tiempos prerromanos, son muy pocos los datos relativos a estos siglos que nos ocupan. Sin embargo, como en otros casos que luego se mencionarán, el arranque de los castros parece vincularse aquí al propio desarrollo del grupo cultural del Soto de Medinilla. Así lo sugieren, en efecto, algunos de los castros conocidos desde hace tiempo: en primer lugar, el de Las Merchanas (Lumbrales), excavado por Maluquer (1968), y que venía siendo considerado como uno de los ejemplos más característicos de los castros de la Segunda Edad del Hierro, con su muralla y su barrera de piedras hincadas; en él ha aparecido recientemente un fragmento cerámico de tipo Soto, lo que da pie a sospechar que el castro hunde sus raíces en la etapa anterior, y que la arquitectura castreña es más antigua de lo que parecía. Tal vez pueda decirse lo mismo acerca del castro de Herguijuela de Ciudad Rodigo (Martín Benito y Martín Benito 1994: 119-120), en el que podría haber una muralla y ha salido alguna cerámica que vendrían a indicar su pertenencia al grupo Soto

Finalmente, otro hallazgo importante se produjo en las inmediaciones del castro del Picón de la Mora, en Encinasola de los Comendadores. A escasa distancia de este poblado defendido también por una muralla y una barrera de piedras hincadas (Martín Valls 1971), los vestigios sotenses corresponden en cambio a un lugar completamente abierto (Martín Valls 1999:
141 y figs. 4 y 11), dando la impresión de un sitio subordinado al castro, o tal vez mejor, de un pobladito previo, que muy pronto fue sustituido por el castro (Fig. 8).

Parece, pues, haber buenos motivos para sospechar, como hace Martín Valls (1999:142), que al menos una parte de los castros salmantinos surgieron precisamente durante la Primera Edad del Hierro y en relación con el grupo del Soto de Medinilla.

Los resultados, todavía inéditos, de las excavaciones llevadas a cabo en la capital salmantina vienen a arrojar luz sobre esta cuestión. Efectivamente, en el casco viejo de la ciudad, en el cerro de San Vicente, existió un poblado del que se conocían ya algunos materiales inequívocamente sotenses (Martín Valls
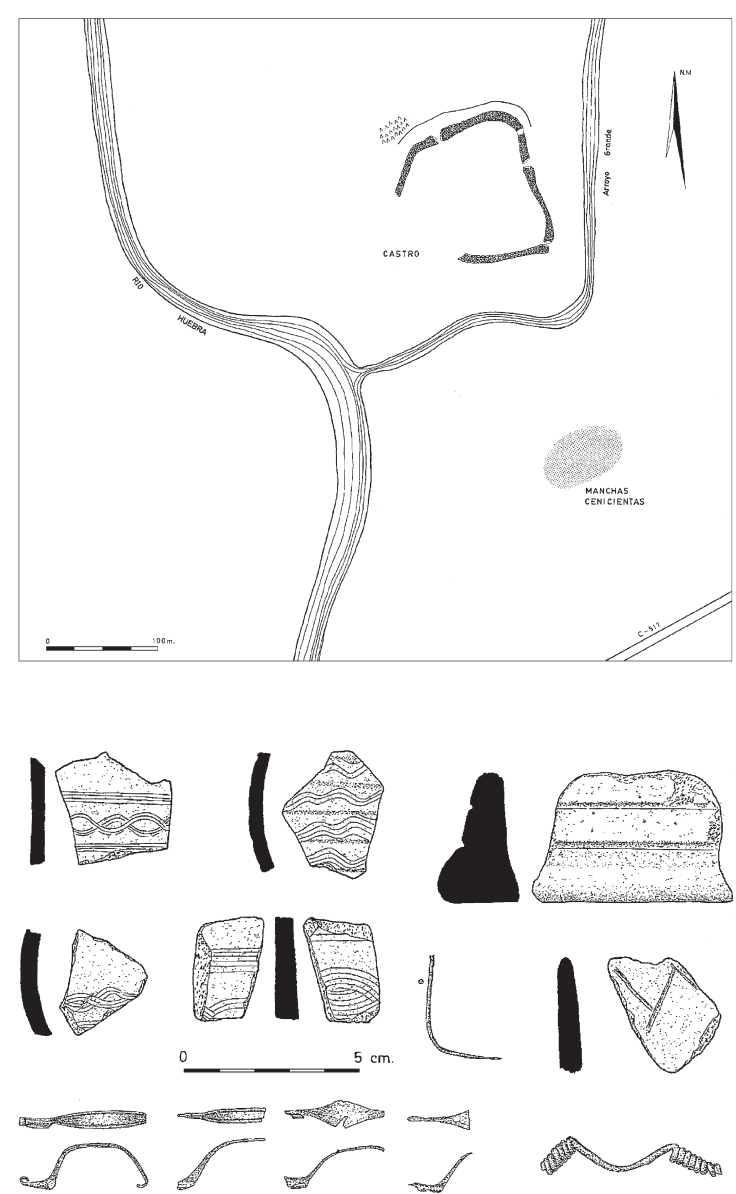

Figura 8.- a) Plano del castro del Picón de la Mora, en Encinasola de los Comendadores (según Martín Valls 1999). b) Materiales hallados en el sector al sur del Picón de la Mora (según Martín Valls, 1986-87). 
et al. 1991: 139-140). Se halla en la plataforma superior de un cerro que, salvo por el sector norte, resulta de difícil acceso por lo escarpado de las laderas, y domina desde la altura un vado del río Tormes y un amplio paisaje en el que entran en contacto las llanuras sedimentarias de vocación cerealista y la penillanura, adehesada desde hace siglos, de aptitud silvopastoril. Pues bien, gracias a la excavación realizada por C. Macarro Alcalde (1999) y estudiada en su Memoria de Grado, sabemos ahora que se trata de un castro, pues en aquella parte septentrional más accesible se trazó un cierre arqueado de unos 80 metros de largo constituido por una muralla de unos 3 metros de grosor, hecha de bloques de arenisca y lajas de pizarra, que debió de rematarse con tapial. Según el citado investigador, la muralla se corresponde con la primera ocupación, del Soto Pleno, siendo desde luego anterior al siglo IV a.C. cuando habría perdido ya su funcionalidad, construyéndose cabañas sobre sus ruinas.

Un caso análogo pudo ser el de Ledesma, en cuya plaza de San Martín se ha encontrado otro poblado del Soto, con viviendas y materiales (Benet et al. 1991) muy similares a los del castro de San Vicente. Lo reducido de la excavación, que se limitó a la plaza de San Martín, no permitió saber si el poblado contaba o no con defensas artificiales que, de haber existido, probablemente se habrían visto muy afectadas por las fortificaciones medievales de la villa y por el desarrollo de la misma.

Resulta interesante citar el cerro de San Pelayo, en Martínamor (Benet 1990), donde parece haber una ocupación de tipo Soto. Este yacimiento, en una pequeña altura, no parece amurallado, de manera que en la formación de los castros puede sospecharse un proceso gradual, tal vez de concentración en ciertos núcleos.

De esta forma, debe plantearse, como hipótesis de trabajo, que la constitución del grupo Soto supuso en esta zona el comienzo de los poblados fortificados. Tales castros, dotados de un aparato defensivo que comprende como mínimo una muralla, acompañada en ocasiones por un foso o por una barrera de piedras hincadas, se establecen siempre próximos a ríos, generalmente entre dos cursos de agua, en lugares de empinadas laderas donde la to- pografía daba ya una seguridad al tiempo que facilitaba el control sobre el terreno circundante. Este tipo de hábitat castreño, que remontaría así a la Primera Edad del Hierro, tendrá un gran arraigo en la zona: al igual que los zamoranos, los castros salmantinos conocerán un largo desarrollo durante la Edad del Hierro (Benet y López Jiménez 2008; Hernández Sánchez 2011), llegando muchos de ellos hasta la romanización.

\subsection{Los castros del occidente zamorano}

Fue precisamente en esta zona meseteña donde primero se advirtió la contraposición entre castros y poblados del Soto. Aquí, y más concretamente en las comarcas fronterizas de Aliste, Carballeda y Sanabria, Gómez Moreno (1904) había descubierto a principios del XX abundantes castros, tipológicamente relacionables con los de zonas limítrofes, pero en los que no se conocían materiales que permitieran mayores precisiones. Retomando esas exploraciones en los años setenta, las prospecciones nos mostraron el contraste entre tales castros, dotados de impresionantes aparatos defensivos, pero siempre parcos en materiales, y los poblados sotenses que se iban descubriendo en la mitad oriental de la provincia —el río Esla marcaría la separación-, ubicados en fértiles tierras cultivables que permitían encontrar con facilidad los materiales característicos.

Laboriosamente, los trabajos de campo efectuados durante un cuarto de siglo (Esparza 1986, 1990, 1995 y 2009; Esparza et al. 1998) han permitido romper aquella inicial dicotomía, apuntándose más bien la idea de que la ocupación de los castros se relaciona también con el grupo del Soto. Así se empezaba a entrever en las excavaciones realizadas en El Cerco (Sejas de Aliste) (Fig. 9), y lo confirman las cerámicas que se han podido recuperar en los castros de Abejera, Brime de Urz, Carbajales de Alba, Carbajales de la Encomienda, Castro de Alcañices, Cubo de Benavente, Escober de Tábara, Fradellos, Fresno de la Carballeda, Gallegos del Campo - cuyo castro de La Mazada nos interesa especialmente-, Manganeses de la Polvorosa, Manzanal del Barco, Milles de la Polvorosa, Muga de Alba, 


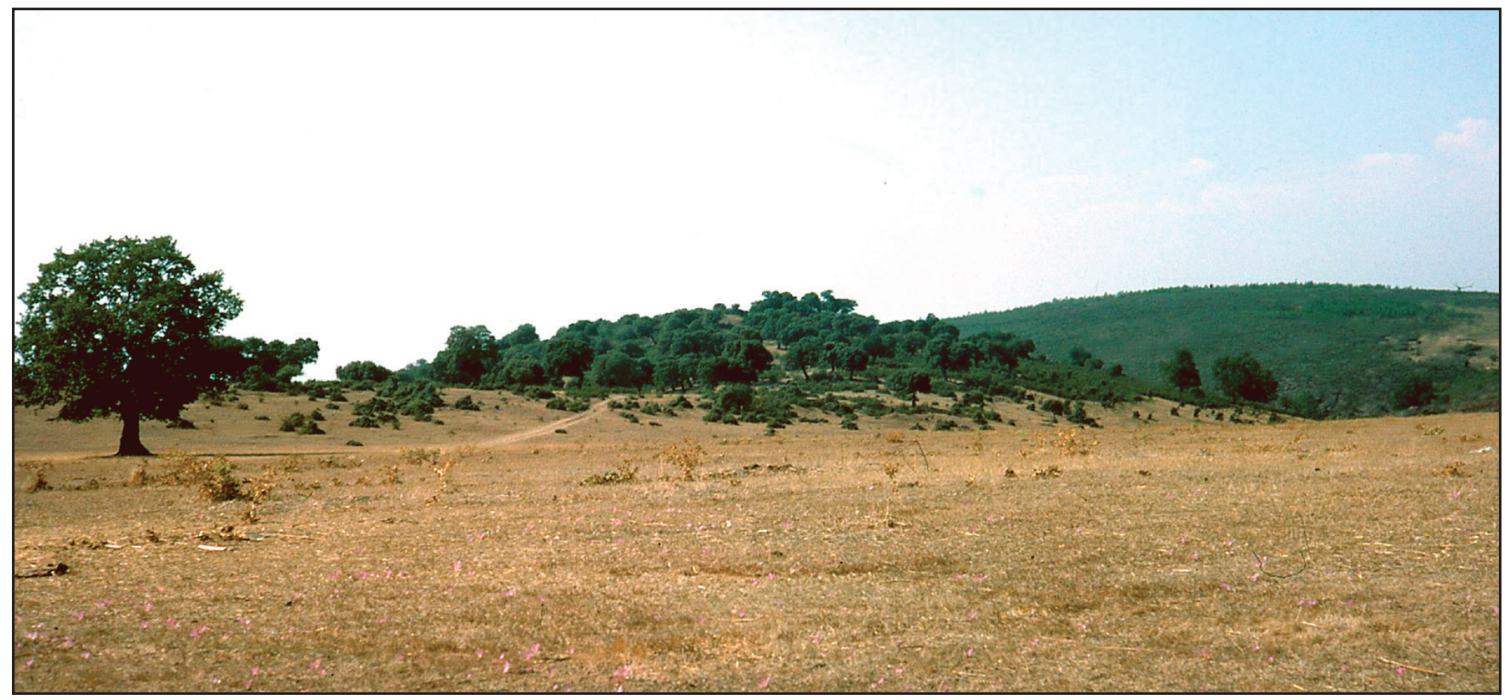

Figura 9.- Castro de El Cerco (Sejas de Aliste, Zamora) (foto de A. Esparza).

San Pedro de la Viña, San Vitero o Vide de Alba. Es preciso reseñar la presencia de estas cerámicas también en otras comarcas mas al sur, por ejemplo en el castro de Fariza, en el Sayago, que nos permite ir a enlazar con el yacimiento salmantino de Ledesma, o en Peñausende, aunque aquí el castillo medieval impide asegurar la existencia de defensas sotenses. Asimismo debe tenerse en cuenta que en la orilla izquierda del Esla, en un punto donde todavía asoma el sustrato rocoso bajo la cobertera sedimentaria, por ejemplo en Fontanillas de Castro, se documenta también un castro amurallado y con cerámica del Soto.

La situación debía haberse clarificado sobre todo cuando en un pequeño sondeo realizado en Camarzana de Tera, Campano y Val (1986) exhumaron cuatro cabañas superpuestas, circulares y de adobe, que remitían, como las cerámicas o la fíbula de doble resorte, al grupo del Soto; pero tal vez porque en el castro no se ve con claridad la muralla, no se han extraído las oportunas consecuencias, que serán mucho más claras al excavarse en dos yacimientos sobre cuya condición castreña no cabe duda alguna, los de Manzanal de Abajo (Escribano 1990) y Moveros (Misiego et al. 1992). El de Manzanal, protegido por muralla, foso y piedras hincadas, proporcionó cabañas circulares y materiales del Soto (Figs. 10 y 11); además, la fecha radiocarbónica obtenida $2580 \pm 60 \mathrm{BP}$ puede ser aplicada a la construcción de las defensas, incluídas las piedras hincadas, que - como ya sospechábamos en los castros de Fradellos, Fresno y Muga de Alba - se pueden vincular así al Hierro Antiguo y además al horizonte Soto.

Por si los datos disponibles no fueran suficientes, en las excavaciones que durante varios años realizaron Celis y Gutiérrez en el poblado del Soto existente en el casco urbano de Benavente, se pudo observar que éste se hallaba delimitado por un potente foso de unos 20 metros de anchura y 5 o 6 de profundidad (Celis 1993: 94), sin que lo limitado del sondeo permitiese documentar si existía también alguna cerca o muralla, que eventualmente se habría situado detrás del foso. Por la misma razón tampoco se pudo asegurar la fecha de construcción de ese foso, pero por los rellenos que contiene, parece ser el cierre del poblado sotense. Como el de San Vicente en Salamanca, se trataría de un castro emplazado en un punto elevado, con un control visual sobre enormes extensiones, dominando en este caso la feraz vega del Órbigo desde el escarpado borde de la terraza.

Finalmente, debe mencionarse, en una del las últimas estribaciones del Macizo GalaicoDuriense, La Corona de Manganeses de la Polvorosa, cuyas defensas no se advertían tampoco en superficie. Al pie de La Corona, en una zona desprotegida que baja suavemente hacia el Órbigo y un arroyo afluente, llamado El 


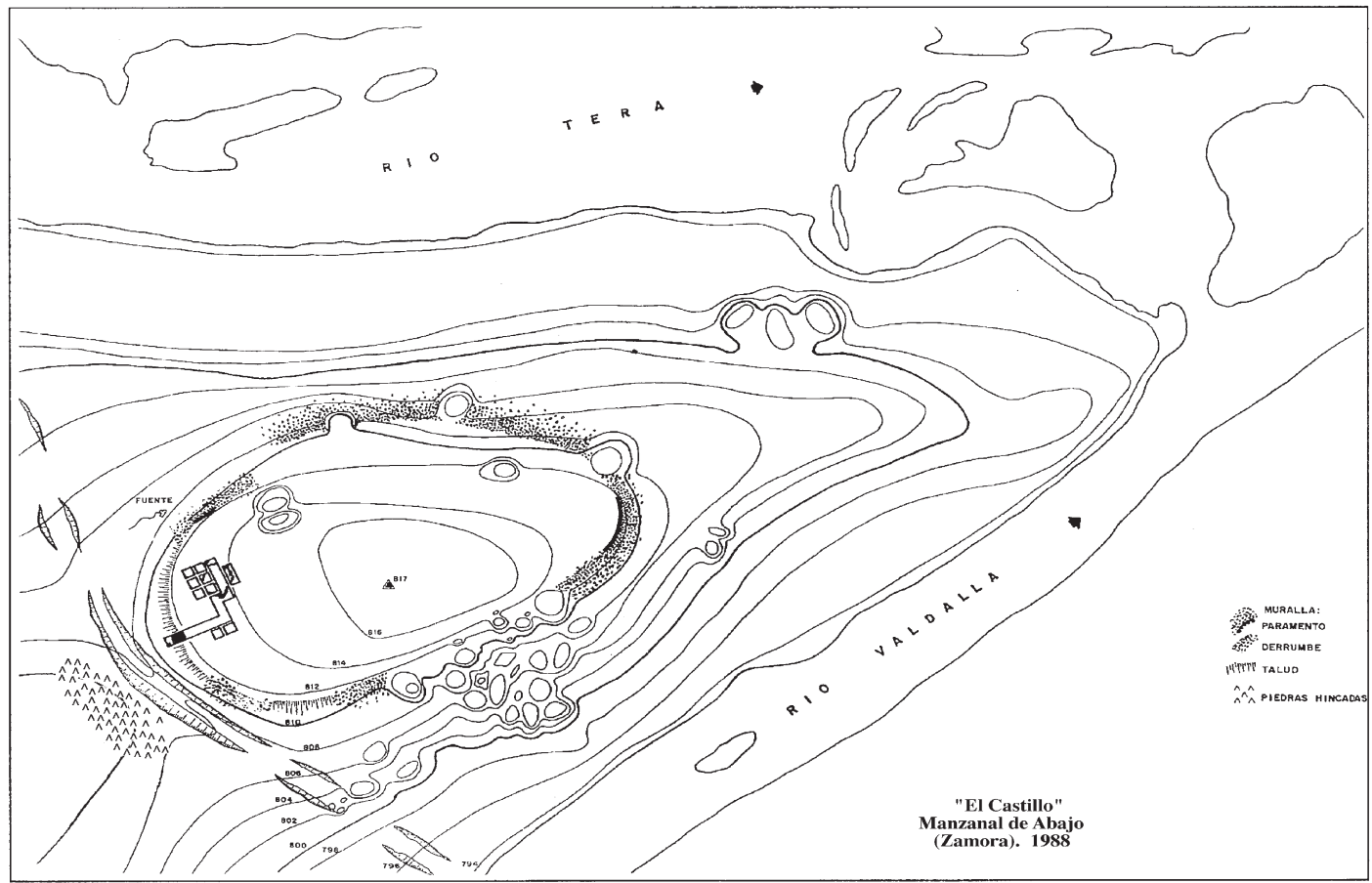

Figura 10.- Plano de "El Castillo", en Manzanal de Abajo (basado en Escribano 1990).

Pesadero, que parecía ser una zona extramuros del castro, se ha excavado una gran extensión que ha permitido conocer las transformaciones de un poblado de la Primera y la Segunda Edad del Hierro (Misiego et al. 1997, 1998 y 2006) (Figs. 14 y 15). La que aquí nos interesa, la Fase I, presenta cuatro subfases o momentos de ocupación, y las características de las viviendas o del equipamiento - cerámicas, fíbulas y otros adornos de bronce, instrumentos de huesos, crisoles y moldes metalúrgicos, etc.--, e incluso los esqueletos infantiles enterrados bajo los pavimentos, nos remiten de inmediato al grupo del Soto. Hay que destacar que en la subfase Id, que parece datable en el primer cuarto del siglo V a.C. (Idem 1999: 58), se construyó una muralla de unos 4,5 m de anchura, con basamento de bloques cuarcíticos, paramentos de adobes colocados a soga y relleno de adobes desordenados. Esta muralla cierra el acceso occidental a este sector, y por su trazado da la impresión de enlazar con La Corona, que habría funcionado así como una acrópolis, de la que lamentablemente nada se conoce.

Estos datos avalados por excavaciones vienen, en suma, a confirmar la integración de los

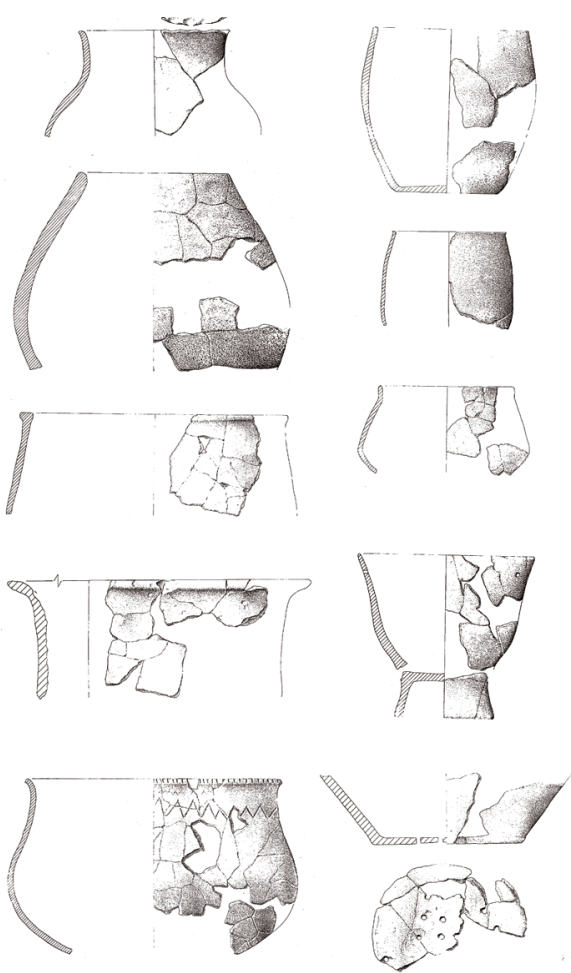

Figura 11.- Cerámicas de "El Castillo", en Manzanal de Abajo (según Escribano 1990). 
castros del oeste zamorano (y alguno de Trasos-Montes, pasada ya la frontera) en el grupo del Soto de Medinilla, en lo que podría parecer un fenómeno de proyección hacia el borde occidental de la región duriense (Esparza y Blanco 2008). Esa visión, no exenta de lógica - una colonización agrícola que progresa desde el centro hacia los bordes de la cuencano debe aceptarse sin discusión, y sobre este problema volveremos en el último apartado de este capítulo.

Del largo desarrollo experimentado posteriormente, a partir del 400 a.C., por este grupo de castros no nos ocuparemos aquí, limitándonos a consignar tres rasgos de interés. En primer lugar, la débil celtiberización de estos castros, es decir, su pequeña participación en el proceso de desarrollo socioeconómico que caracterizará las zonas de la Cuenca del Duero en los últimos siglos antes de Cristo; de ahí la escasísima presencia que tiene en esta zona la cerámica pintada celtibérica, aunque algunos castros más orientales, o que tienen en su entorno terrenos de aptitud agrícola mayor, se integran claramente en ese proceso, como se ha comprobado en Manganeses de la Polvorosa, en su espléndida fase II. En segundo lugar, la probable fundación de castros nuevos, como los de las cumbres de la sierra de la Culebra o algunos de Sanabria: el castro de As Muradellas, en Lubián (Esparza 1986: 210-216), sería un buen ejemplo, y sobre todo El Castro de San Martín de Castañeda o El Castro de Ferreras de Arriba, donde se vislumbra un momento final de la Edad del Hierro que tiene su punto de referencia, al otro lado de la sierra de la Cabrera, en la ya citada Corona de Corporales (FernándezPosse y Sánchez-Palencia 1988). Finalmente, la romanización de algunos castros, especialmente los que disponían de un cierto potencial, como los de Manganeses (fase III) o Sejas.

\subsection{Los castros del piedemonte de los Montes de León}

En la provincia de León, como en la de Zamora, la investigación ha ido acentuando durante mucho tiempo esa situación de contraste, varias veces mencionada, entre los poblados del grupo Soto que abundan en las tierras sedimenta- rias y los castros documentados por centenares en las zonas más montañosas (Gutiérrez 198687; Celis 1996 y 2002). De éstos, desgraciadamente apenas se conoce otra cosa que su emplazamiento y algunos materiales que permiten suponer que estaban ocupados en momentos avanzados de la Edad del Hierro (Celis 1996: 56, mapa 2), lo que hace especialmente difícil afrontar lo sucedido en los siglos que aquí nos ocupan. Por ello, nuestra aproximación seleccionará la zona que se halla al pie de los Montes de León, donde hay un poco más de seguridad en cuanto a la correspondencia de los castros al Hierro Antiguo, aunque la falta de excavaciones sigue permitiendo todavía interpretaciones muy diferentes. Así, en uno de los trabajos más importantes, Almudena Orejas (1996: 61-70) defiende que estos castros más occidentales son coetáneos, pero diferentes, de los poblados del Soto: basándose en el análisis territorial, sostiene que hay diferencias significativas entre unos y otros, ya que frente a los poblados sotenses, que destacan muy poco sobre la vega, los castros alcanzan valores superiores en altitud, tanto absoluta como en relación a la vega, pero sobre todo tienen una superficie habitable menor, puesto que una parte del sitio en el que se emplazan ha sido ocupada por las obras defensivas; además, el análisis de los recursos potencialmente disponibles en torno a poblados y castros apoyaría la mencionada dualidad.

Creemos posible, sin embargo, defender la unidad entre esos yacimientos que se contraponen: unos y otros se integrarían en el mismo grupo cultural, el del Soto, siendo las diferencias simplemente de matiz, en relación con peculiaridades geográficas o de otra índole más compleja. Si partimos de una concepción politética de las entidades arqueológicas, no puede extrañar que yacimientos del mismo grupo compartan muchos de los rasgos definitorios, pero no el cien por cien .Una vez más, habremos de defender, como hipótesis de trabajo, que los primeros castros de esta zona de los Montes de León debieron de tomar parte en la constitución del grupo del Soto, y en este sentido, debemos mencionar que algunos de los castros estudiados por la mencionada autora, concretamente los ubicados en las localidades de Castrotierra de la Valduerna, Pedredo y Sopeña, han dado 
materiales característicos del Soto de Medinilla, y otro tanto hay que decir de los de Pobladura de Yuso y Castrocontrigo.

La divergencia en las interpretaciones se explica, insistimos, por lo superficial de nuestro conocimiento, de ahí que sea imprescindible citar el caso del pobladito de Sacaojos, en Santiago de la Valduerna, que seguramente hace inclinar la balanza: J.M ${ }^{a}$ Luengo (1961) lo dio a conocer como un verdadero castro, y posteriormente se pudieron reconocer en él las características de una estación del Soto de Medinilla, tanto por su materiales cerámicos como por su arquitectura doméstica, con cuatro niveles de cabañas circulares de adobe, los primeros con zócalos de piedra. Pues bien, las excavaciones recientemente efectuadas (Misiego et al. 1999) en este yacimiento han confirmado que, en efecto, es un poblado del grupo Soto, y que durante una ocupación del Soto Pleno (s. VII-IV a.C.) se levantó un cierre consistente en una muralla de tapial, detrás de la cual unos agujeros de poste sugieren la posible existencia de una estructura de madera a modo de camino de ronda. Así pues, como en el cerro de San Vicente (Salamanca), o en los castros zamoranos que antes vimos, se esfuma la diferencia entre castro y poblado del Soto, confirmándose que fue durante el desarrollo de esta cultura cuando surgieron los poblados fortificados.

Los sitios que hemos mencionado podrían de nuevo dar pie a hablar de una proyección de este grupo cultural hacia el Noroeste de la Meseta, que aquí se habría hecho remontando los afluentes -Eria, Duerna, Tuerto- del río Órbigo, sin que sepamos a ciencia cierta si lo castros que están ya metidos en las zonas montañosas, por ejemplo en la sierra de la Cabrera, son también de este mismo momento, o si fueron construidos en momentos bastante más tardíos, prerromanos, como sucederá con los de Corporales, San Juan de Paluezas, Borrenes, etc. Enorme importancia revisten, en este sentido, algunos yacimientos de El Bierzo —Paradela del Río, Toral de Merayo, Castro Ventosa, etc.- donde se ha señalado la presencia de cerámicas del Soto (Mañanes 1977), pero estas citas todavía no se han comprobado, salvo en el castillo de Ponferrrada, donde parece segura su existencia (Celis 1996: 53). De confirmarse la inclusión de estos castros bercianos en el grupo del Soto, encontrarían plena justificación algunos materiales broncíneos que, desprovistos de contexto seguro, se conocen en la comarca, como las puntas de lanza que componían el depósito de Bembibre o la espada de tipo Vénat hallada en Villafranca del Bierzo, cuya tipología los lleva al Bronce Final IIIb.

\section{Elementos para un análisis de conjunto}

\subsection{El poblamiento castreño}

Si los trabajos de inventario y el estudio cronotipológico de los castros están todavía poco adelantados, no es de extrañar que no se haya avanzado mucho en la aplicación de los métodos de análisis espacial, que deben basarse en un catálogo razonablemente completo y en una cierta seguridad en cuanto a la datación de los yacimientos

De esta forma, no se dispone de un estudio de conjunto del hábitat castreño de la zona que nos ocupa, y los que se han realizado en algunos sectores son muy desiguales en cuanto a profundidad y metodología. Al menos, podemos contar con una aproximación somera para los castros salmantinos (Álvarez-Sanchís 1999: 120-122), mientras que una parte de los zamoranos fueron objeto de un ensayo (De Carlos Izquierdo 1990: 175-227) muy limitado por imprecisiones en la localización, por la cartografía disponible y la propia escala de trabajo, factores que hacen poco aprovechable el análisis, por ejemplo, de la pendiente del terreno, de la distancia de los castros al agua, etc., por lo que debe esperarse hasta que concluya el estudio mediante SIG que actualmente tenemos en curso. En la zona de León, Y. Álvarez González (1993) estudió con rigurosa metodología un grupo de castros de la cuenca de Noceda, pero se carece de elementos que corroboren la datación de los yacimientos, para algunos de los cuales se apunta una cronología prerromana, seguramente de los últimos tiempos de la Edad del Hierro; en cuanto a los yacimientos de la zonas al pie de los Montes de León, han sido caracterizados por A. Orejas (1996), cuyo trabajo será referencia imprescindible.

Por lo que se refiere al patrón de asentamiento, cabe mencionar, en primer lugar, que estamos ante un poblamiento disperso y poco 
jerarquizado, en el que puede advertirse una cierta distribución lineal, en relación con los cursos fluviales. Aunque es fácil incurrir en el subjetivismo, cuando se visitan los castros alineados como un rosario a lo largo del Duerna, el Eria, el Tera, el Aliste, el Huebra..., se tiene la impresión de que esos eran también los ejes de la comunicación. No se olvide, sin embargo, que en las penillanuras del oeste los ríos han sufrido un fuerte encajamiento, por lo que ese relieve tortuoso podría dificultar los desplazamientos, siendo tal vez conveniente alejarse de ellos. Algunas estimaciones acerca de la separación entre poblados vienen a coincidir en que no se rebasan los $10 \mathrm{~km}$, siendo frecuentemente de unos $3 \mathrm{~km}$, aunque tampoco es raro advertir una mayor proximidad entre algunos castros que, aparte de complicar el uso de técnicas espaciales, hace inevitable preguntarse si eran estrictamente simultáneos: la cercanía de dos castros como los de Riomanzanas, por ejemplo, ¿no se deberá a que uno de los dos fracasó, cambiándose el poblado a un sitio mas favorable?

Otro rasgo recurrente es el intervisibilidad de los castros. Sin llegar a casos extremos como los de Sanchorreja (Fig. 4) o La Mazada (Fig. 12), que gozan de un enorme control visual, lo cierto es que desde muchos poblados se divisa otro u otros. Incluso suponiendo una cobertera arbórea más desarrollada que en la actualidad, este parece un hecho común.

En cuanto a la ubicación concreta, hay un clarísimo predominio de los emplazamientos que comúnmente se denominan "defensivos". Tradicionalmente se ha sobreentendido que lo que se buscaba era proteger el acceso al castro situándolo en un punto donde la propia naturaleza introduce ya un cierto grado de dificultad: cerros destacados por su aislamiento, promontorios alargados a los que sólo se llega fácilmente por un sitio, espigones ubicados en la confluencia de ríos, meandros encajados, bordes de ladera, etc. No es raro detectar que junto a esa presunta preocupación defensiva hay también un deseo de dominar un vado, o de controlar visualmente una cierta extensión de terreno. Es más, a veces, la buena disposición del sitio - relativamente plano, próximo al agua, orientado hacia la solana, etc.- parece haber predominado sobre la seguridad, pues hay castros que, aun siendo de acceso incómodo, están situados a menor altitud que otras elevaciones muy próximas, desde las que podrían ser amenazados: en unas cuantas ocasiones, estos castros occidentales parecen estar al alcance de un armamento sencillo pero eficaz como es la honda, cuyos proyectiles hemos creído detectar alguna vez (Esparza 1986: 251-254). Estas dudas han motivado aquellas consideraciones con las que se abría este capítulo acerca del verdadero carácter de los castros. A. Orejas, por ejemplo, sostiene que lo que se pretendía era delimitar más que defender, por lo que se buscaban sitios donde la propia topografía proporciona ya una buena delimitación del poblado. Desde luego, otros factores parecen haber intervenido también en la localización de los castros, como los recursos disponibles en los alrededores, y hasta se podría apuntar que al elegir elevaciones de una cierta altura (no demasiada en la mayoría de los castros de la Primera Edad del Hierro), tal vez se estuviese evitando el encharcamiento de las zonas más bajas, que en unas condiciones de mayor pluviosidad como las de aquella época, no sería pequeño problema.

El dominio sobre el terreno se relaciona lógicamente con la altitud. La gran mayoría de nuestros castros —una vez más Sanchorreja es excepcional- se asienta por debajo de los 950 metros sobre el nivel del mar, dando la impresión de que los que están a más altura corresponden a los momentos finales de la Edad del Hierro. Pero este dato no es muy significativo si no se sabe cuál es la altitud media de las comarcas en las que se hallan los castros, o lo que es lo mismo, cuánto descuellan en el paisaje: como antes se dijo, no es mucho, pues no se suelen superar los 50 metros, aunque algunos castros como la Corona de Lucillo o los Castillejos de Sanchorreja sobrepasan con mucho el centenar de metros. La Mazada nos ilustra algo que sucede a menudo en las zonas de penillanura: por su parte más accesible, apenas destaca unos 50 metros, pero en cambio se alza 100 e incluso 200 metros por encima de los arroyos que corren a sus pies.

En el estudio de los factores de localización, es decir de todos estos elementos que debieron de ser tenidos en cuenta a la hora de elegir un 


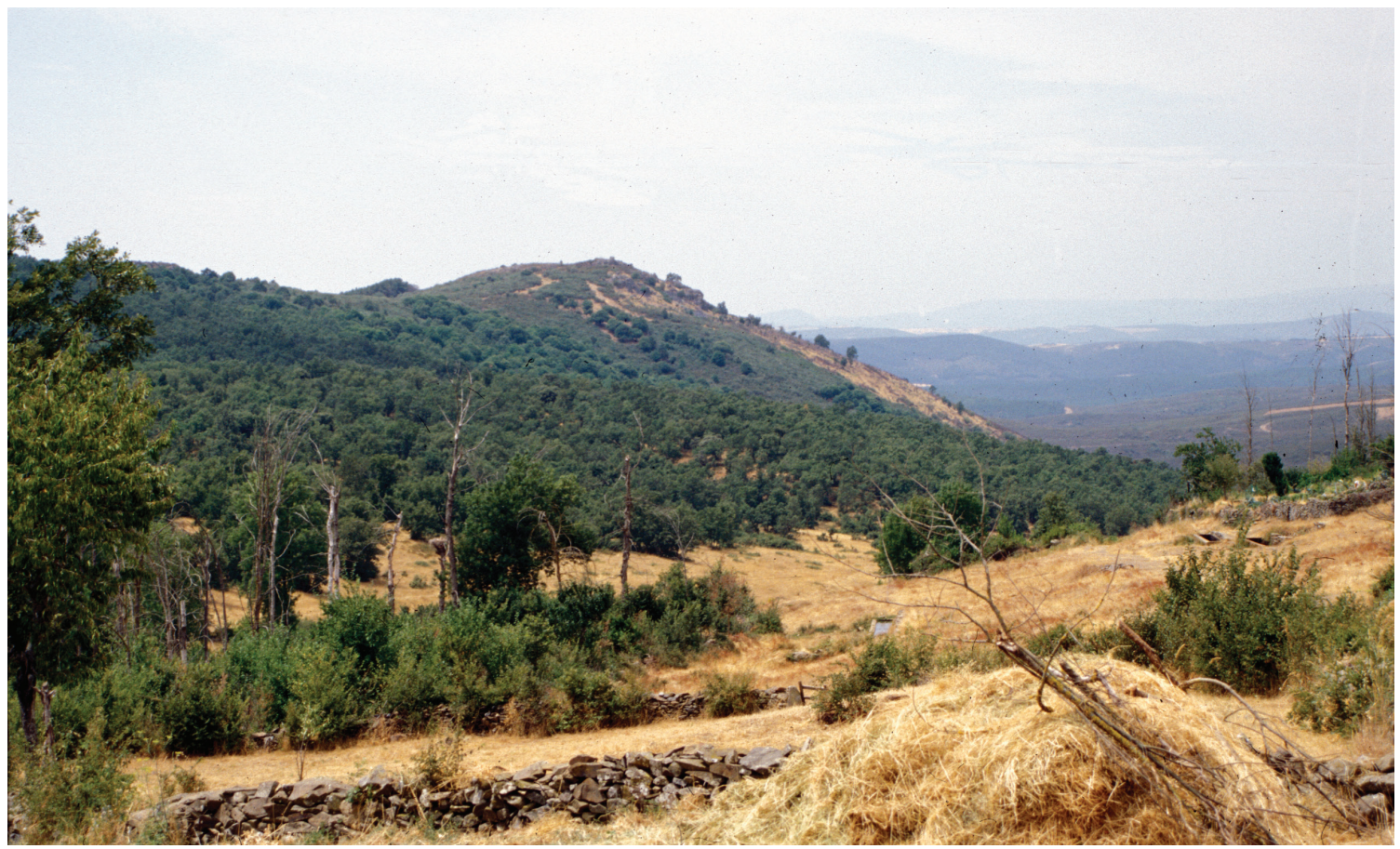

Figura 12.- Castro de La Mazada (Gallegos del Campo, Zamora) (foto de A. Esparza).

emplazamiento determinado, se ha insistido especialmente en los más relacionados con la subsistencia. En los castros salmantinos, alguno de los cuales debe de remontar a nuestra primera Edad del Hierro, Álvarez Sanchís ha mostrado gráficamente el fuerte predominio de los terrenos de pastos dentro de los territorios teóricos de explotación, y De Carlos también lo señala para los zamoranos, aunque los de Aliste tendrían mayor potencial agrícola. Más preciso, por recurrir sistemáticamente a técnicas cuantitativas, es el trabajo de A. Orejas, que ha evaluado así la altura, la superficie, el grado de control visual que se obtiene desde cada yacimiento, y sobre todo los recursos potenciales. La comparación de los porcentajes que en un entorno referencial de $2 \mathrm{~km}$ de radio alcanzan los terrenos de secano, de regadío y los de "captación" (es decir, susceptibles de aprovechamientos recolectores, forestales, mineros, etc.) nos llevaría a concluir una preferencia por las tierras de secano, que se completaban con las regables según las posibilidades locales, y con las zonas de captación, que a veces se superponen a las primeras. Veamos como ejemplo algunas de las estimaciones de dicha autora:
Secano Regadío Captación

$\begin{array}{lrcc}\begin{array}{l}\text { Castrotierra } \\ \text { (CND28) }\end{array} & 55,25 \% & 44,74 \% & 9,55 \% \\ \begin{array}{l}\text { Pedredo } \\ \text { (CND48) }\end{array} & 81,28 \% & 16,16 \% & 10,35 \% \\ \begin{array}{l}\text { Sacaojos } \\ \text { (CND29) }\end{array} & 46,18 \% & 49,52 \% & 4,30 \% \\ \begin{array}{l}\text { Sopeña } \\ \text { (CND65) }\end{array} & 60,19 \% & 39,80 \% & 6,05 \%\end{array}$

En nuestros trabajos en curso en la zona de Zamora estamos utilizando otro tipo de aproximación, pues nos basamos en los mapas de clases agrológicas. Tales clases, que han sido definidas por los especialistas a partir de criterios climáticos, topográficos, edáficos, etc., reflejan la vocación o aptitud para el aprovechamiento, especialmente agrícola. Pues bien, en el entorno de los castros zamoranos no existen los terrenos de las clases I y II, las de mayores posibilidades agrícolas, siendo relativamente pequeños los porcentajes de la clase III. Las clases IV y V que por su falta de profundidad, por estar demasiado sometidas a la erosión, etc., presentan ya limitaciones importantes para la agricultura, sí 
están representadas. Pero sobre todo, lo que predomina en el entorno inmediato de estos castros son los terrenos de las clases VI y VII, cuya vocación es de pastizales o incluso forestal. En la figura 13,1 se reflejan las mediciones porcentuales hechas en territorios convencionales de 2000 metros de radio en torno a algunos castros, llamando la atención la gran importancia que en la mayoría de los casos reviste la suma de las clases VI, VII y VIII (improductivo, generalmente por la desnudez de la roca). Además, podemos ver en la fig. 13,2 los resultados de las mediciones hechas para un mismo castro, el de La Mazada, pero probando distintos radios: en el entorno más inmediato, tan escarpado, apenas hay recursos potenciales, que tienen ya una cierta presencia a partir de 1500-2000
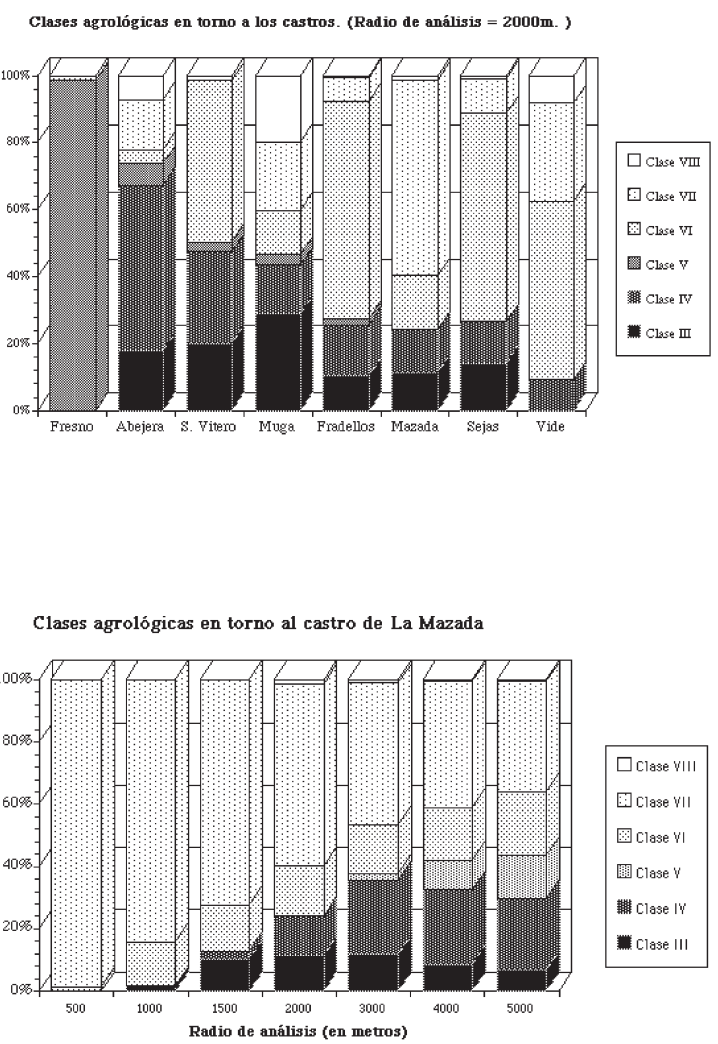

Figura 13.- a) Estimación del potencial económico de algunos castros zamoranos. b) Variación del potencial económico del castro zamorano de La Mazada en función de la distancia. metros de radio, empezando a decrecer la importancia de las clases III y IV a partir de los 3000 metros.

Así pues, la búsqueda de una cierta cantidad de tierra cultivable, aunque fuese de no muy buena calidad, parece haber estado siempre presente en la elección de sitio. La distancia al agua, o la presencia de minerales de cobre, estaño e hierro parecen haber intervenido también, aunque la primera no es totalmente decisiva: el abastecimiento humano pudo hacerse gracias a manantiales como los que hoy todavía se ven en algunos castros o en sus inmediaciones, y los ganados podrían abrevar a distancias no muy grandes, dada la relativa cercanía a ríos y arroyos. En cuanto a los minerales - entre los que no hay que olvidar las pepitas de oro que podrían batearse en los ríos que bajan del Macizo Galaico-leonés- no sería necesario que los hubiese en el propio emplazamiento (como sucede en La Mazada), siendo suficiente con que los hubiese en los alrededores, como ocurre en tantos castros de las penillanuras occidentales.

Casi siempre, en el lugar elegido se construyó un solo recinto, es decir un único espacio encerrado tras la muralla; pero algunos castros se escapan a esa regla general, como el de Sanchorreja, o La Mazada. Tales excepciones son importantes, porque sugieren algún tipo de diversificación de funciones económicas, sociales, etc., hoy desconocidas. Desde luego, una explicación muy simple, que nos llevase a suponer un desbordamiento de la primera muralla por un aumento demográfico o por algún tipo de segregación social, no resulta aceptable, a la vista del sector excavado en El Pesadero, junto a La Corona de Manganeses de la Polvorosa: aquí, lo que parece ser el verdadero poblado estaría fuera del recinto más elevado, pero andando el tiempo llegó a ser encerrado también por una muralla.

Volviendo al caso más general, el tamaño de los recintos castreños es variable, desde los pequeños, de menos de 1 ha, a los de enorme extensión, como Sanchorreja, pasando por una buena cantidad de castros de entre 2 y 6 has. Desde luego, si se quiere discutir la posible jerarquización del poblamiento, es necesario sistematizar el estudio de este aspecto del tamaño de los poblados, y de forma más 
precisa que la usual. Generalmente nos limitamos a medir el interior del recinto, pero A. Orejas descuenta lo que ocupan los elementos artificiales existentes para concluir proponiendo cual fue estrictamente la superficie habitable. A través de ésta se llega además a cálculos aproximativos acerca de la población que habitaba los castros, que la autora estima entre 300 y 400 personas en Castrotierra, entre 110 y 147 en Pedredo, y entre 187 y 250 en Sopeña. Estos cálculos, mucho mejor fundamentados, corrigen a la baja las estimaciones que habíamos tanteado años atrás para los castros zamoranos: si queremos hacernos una idea del número de moradores de un castro, un práctico índice sería el de 150-200 habitantes por ha de superficie habitable.

La investigadora que venimos citando ha aprovechado los cálculos demográficos de los diversos castros para llegar a estimar también la población total de la zona por ella estudiada - entre 1055 y 1108 individuos en la zona al oeste del Órbigo - y la propia densidad de la población del territorio, que quedaría entre 0,91 y 1 habitantes $/ \mathrm{Km}^{2}$. Para entender mejor lo que estas cifras significan, digamos que hacia 1970, la densidad de población en esa comarca o en las vecinas era de unos 8-10 habitantes $/ \mathrm{Km}^{2}$.

Por desgracia, muchas de las cuestiones que comentamos se ven oscurecidas por la dificultad de datar con precisión los castros, ya que los materiales arqueológicos (máxime los aparecidos en prospección) carecen del poder resolutivo necesario para ello. La sensación obtenida de contemporaneidad entre poblados es probablemente ilusoria, ya que no es seguro que todos ellos existieran al mismo tiempo, sino que debieron de escalonarse irregularmente a lo largo de varios siglos. A la vista de yacimientos bastante próximos nos preguntábamos si eran estrictamente vecinos, o si, por el contrario, son el resultado de diferentes intentos, algunos de ellos fracasados, de establecerse en el territorio. Pues bien, aunque aceptemos sin la más mínima reserva que la elección de emplazamiento se realizaba de manera racional, no por ello debe suponerse que las gentes castreñas nunca se equivocaban en sus cálculos, o que no variaban las circunstancias que encuadraron la decisión inicial.
Estas suposiciones se justifican a partir de la experiencia histórica: los despoblados medievales, por ejemplo, constituyen la prueba de intentos de colonización que fracasaron, por razones que a veces se explicitan en la documentación; nos resulta especialmente ilustrativo el proceso - mucho más tardío y complejo que nuestros castros - de creación de las villas guipuzcoanas en los siglos XII al XIV. A través del estudio de Arizaga Bolumburu (1990) podemos ver como incluso en las condiciones técnicas, demográficas, económicas y sociopolíticas de esta época, en cuatro de las veinticinco fundaciones (el $16 \%$ ), la elección de lugar no resultó afortunada, debiéndose cambiar de sitio; en un caso, por incendio, y en otros, porque no se alcanzaban las expectativas iniciales. En dos ocasiones se ha podido establecer la cronología del fracaso: la decisión del traslado se tomó a los nueve años en una villa y a los cuarenta y nueve en la otra; es interesante reseñar también que en una ocasión, el traslado se tradujo en un nuevo fracaso, volviéndose finalmente al lugar escogido la primera vez.

Así pues, parece necesario preguntarse cuántos poblados prehistóricos habrán tenido que ser abandonados por un incendio, por haberse secado el manantial inmediato, o por la precariedad de unos recursos que se habían estimado suficientes y resultaron no serlo tanto. Los nuevos castros, coetáneos, pero no simultáneos con los abandonados, terminarían confundiéndose con ellos en un "palimpsesto" que la investigación arqueológica no acierta a desentrañar fácilmente.

\subsection{La arquitectura defensiva}

Aunque no se han realizado excavaciones específicamente dirigidas a conocer las características estructurales de murallas, fosos, etc., podemos al menos esbozar sus rasgos generales, insistiendo nuevamente en que resulta prematuro emplear expresiones como "muralla", cuando a veces solo se percibe un elemento de cierre que podría haber servido como protección contra alimañas; cabe alguna duda incluso sobre el término "poblado", cuando no conocemos lo que hay en el 
interior de la mayoría de los yacimientos, de los que ni siquiera se sabe si todos estaban ocupados permanentemente, algo que resulta problemático en algún caso, por su altitud. Reiteramos también la dificultad de la cronología, que afecta especialmente a los castros salmantinos, donde no parece prudente remontar las potentes murallas dotadas de talud al primer Hierro, en el que sin embargo han debido de arrancar algunos castros; en cuanto a los castros leoneses son en este aspecto arquitectónico un poco menos conocidos, tal vez por las condiciones concretas de erosión, vegetación, etc., de forma que en ellos no siempre hay seguridad acerca de los elementos de cierre, pues si a veces se perciben claramente, en otros casos parecen más bien aterrazamientos.

El elemento más claramente perceptible de los castros es la muralla, hecha casi siempre a base de piedra, concretamente de lajas de pizarra metidas a tizón, o bien de bloques de cuarcita, o de granito, según sea el sustrato rocoso local. Aunque estas murallas no sean tan cuidadas y potentes como las de los castros de cronología más avanzada, parece que se construyeron con una técnica mínimamente cuidada, a base de dos paramentos, exterior e interior, con mampostería en seco bien aparejada, y un relleno de piedra más menuda, colocada en capas ordenadas con menos cuidado. Algunas veces, la erosión ha ocultado las murallas bajo un lomo de apariencia terrera, pero la verdadera estructura asoma aquí y allá. Recuérdense sin embargo los casos ya mencionados en los que se alzó una estructura a base de adobes - Manganeses - o de tapial - Salamanca - sobre un basamento de piedras (Fig. 15), o simplemente una defensa de tapial, como en Sacaojos.

En la mayoría de los casos, la muralla parece asentada directamente sobre la roca, aunque hemos podido ver reiteradamente que la muralla no se construía en la parte más alta, relativamente plana, de los castros, sino que se hacía en plena pendiente, allí donde se obtenía la máxima visibilidad y dificultad de acceso. Ello obligó frecuentemente a hacer recortes en la roca para favorecer el asiento del muro, y también explica la importancia de los derrumbes actualmente visibles, que a veces tienen varios metros de anchura. Sólo algún corte reciente, como en el castro abulense de La Mesa de Miranda, permite alguna precisión más (Fabián 2005b; Álvarez-Sanchís 2007). Por lo común, la muralla encierra por completo el poblado, pero en ocasiones el sitio es tan arriscado que basta con proteger un sector, y entonces sólo hay, al menos aparentemente, una especie de arco de muralla en ese tramo concreto, no siendo raro que en tal sector más comprometido exista delante de la muralla alguna otra barrera defensiva, como un foso o un campo de piedras hincadas.

El acceso al poblado se hacía a través de unas entradas que hoy se perciben simplemente como interrupciones de la muralla, sin que se haya excavado nunca en una zona tan propicia. Se supone que en ellas debió de haber unos portones de madera, y también se ha especulado con la existencia de algún tipo de parapeto o protección a base de postes en la parte superior de la muralla, pero en realidad no se sabe como remataba ésta. Desde luego, las dimensiones del muro parecen importantes, a juzgar por algunos retazos conservados, y por el propio volumen del derrumbe, se podrían estimar en un grosor mínimo de dos metros y medio, habiéndose repetido observaciones en torno a los 3-4 $\mathrm{m}$ y aun superiores. En cuanto a la altura, se han conservado en ocasiones más de $2,5 \mathrm{~m}$, pudiéndose calcular prudentemente unos $3 \mathrm{~m}$. Añádase la mención de algunos elementos especiales, como una especie de torreones probablemente no huecos, sino macizos engrosamientos de la muralla- que advertimos en algunos castros, especialmente de Aliste, y también un acceso en forma de rampa pegada a la muralla que se intuye en el Picón de la Mora.

Un foso, que debió estar profundamente excavado aunque hoy aparezca colmatado casi por completo, complementa a menudo el sistema defensivo. Aunque también aparece en los castros leoneses, es especialmente frecuente en los castros de las penillanuras, especialmente en Zamora, donde también llama la atención la presencia de fosos en sectores distintos e incluso de dobles fosos o zanjas paralelas. Debe decirse que, aunque haya un recinto completamente cercado de muralla, 


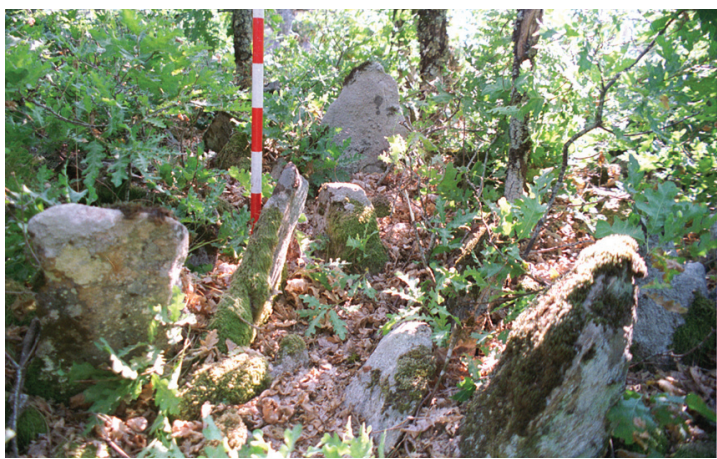

Figura 14.- Piedras hincadas del castro de As $\mathrm{Mu}-$ radellas (Lubián) (foto de A. Esparza).

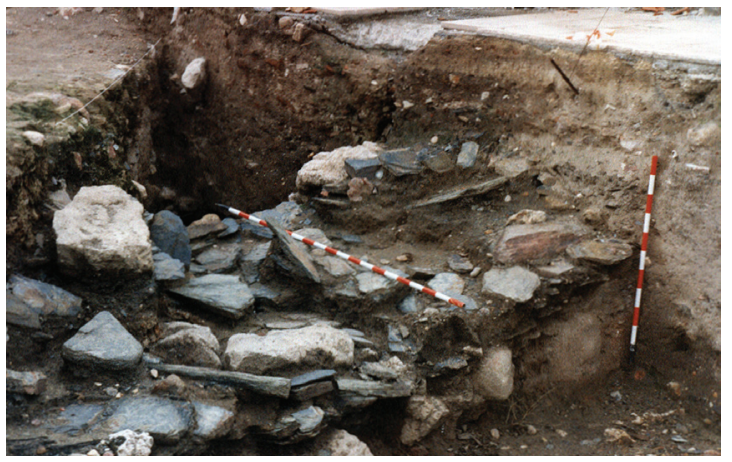

Figura 15.- Muralla del castro del cerro de S. Vicente (Salamanca) (foto de C. Macarro y C. Alario).

los fosos son, en cambio, parciales, limitándose a los sectores imprescindibles.

Finalmente, nos referiremos a un sistema defensivo, las llamadas piedras hincadas, que vemos aquí con cierta frecuencia. Se trata de unas barreras formadas, como su nombre indica, por bloques prismáticos de granito o puntiagudas lajas de pizarra, según las zonas, bien clavadas en el suelo, verticales o a veces con inclinaciones cruzadas. Suelen asomar entre quince centímetros y medio metro, y se disponen en franjas que pudieron llegar al centenar de metros de anchura y de longitud (Fig. 14). Estos campos de piedras hincadas se hallan en ocasiones delante de la muralla, pero otras veces se pueden encontrar delante o detrás del foso. La tradición popular interpreta tan curioso artilugio como una defensa contra la caballería, si bien Gómez Moreno (1904: 149) no llego a concretar tanto, considerándolo como un obstáculo para impedir que el enemigo se acercase rápidamente contra el muro, idea defendida, recientemente, con algunos argumentos tácticos y defensivos (Ruiz Zapatero 2003).

No las hay en Sanchorreja, aunque aparecerán en algunos de los grandes castros abulenses de la Segunda Edad del Hierro, y faltan también en la actual provincia de León, lo que contrasta mucho con la abundancia de este sistema en los castros de Zamora y Salamanca. Como este sistema se conoce también en otras zonas peninsulares, habiendo aparecido últimamente en el Valle del Ebro - especialmente en Els Vilars (Arbeca, Lérida), un poblado de la Primera Edad del Hierro (Alonso et al. 1988) - y en el SO, la bibliografía al respecto es abundante, sobre todo tras los trabajos pioneros del investigador irlandés Harbison (1971), quien desde una perspectiva difusionista sostuvo su origen en el interior del continente europeo, su extensión hacia diversas regiones occidentales, entre ellas la Península Ibérica, y, una vez aquí, la progresión en sentido Este-Oeste (Alonso et al. 2003).

En dos estudios de conjunto (Esparza e.p. y 2003) se revisa la bibliografía al respecto. Ahora interesa únicamente mencionar que, aunque sigan levantándose estas barreras en tiempos más recientes, parece haber una clara relación entre piedras hincadas y castros del Primer Hierro, tanto en los de la zona de Soria que serán tratados en otro capítulo, como en los de Zamora-Salamanca. Según ya vimos, algunos de éstos -Fradellos, Muga, Fresno, Manzanal, y seguramente El Picón de la Mora y Las Merchanas- se vinculaban al Soto Pleno, por lo que irían a los siglos VII-V a.C., y la fecha radiométrica del castro zamorano de Manzanal, 2530 $\pm 60 \mathrm{BP}$, esto es, el intervalo 808(764)409 cal BC, lo avala. A decir verdad, en estos momentos no es posible decir si la hipótesis de Harbison es válida, pues desde el punto de vista estadístico, no puede decirse que las fechas radiocarbónicas de Manzanal, de los castros sorianos y del poblado ilerdense de Els Vilars sean diferentes.

En ese mismo trabajo se recoge la división existente entre los investigadores al considerar que se hicieron contra jinetes o contra infantes. Viendo las condiciones de unos castros y otros, no es aventurado considerar que, 
en general, se trataba de impedir un acceso súbito, probablemente dirigido más contra acciones de rapiña, mediante golpes de mano, que contra verdaderos ejércitos. Desde luego, hay dos hechos importantes: en primer lugar, este sistema se seguirá empleando en el Noroeste peninsular, desde Asturias y Galicia a Zamora y Tras-os-Montes, en poblados romanos construidos en el s. I d.C. en relación con la minería del oro, en los que ya no cabe hablar de verdadero valor militar de las "defensas". Murallas, fosos y piedras hincadas, que se multiplican espectacularmente, podrían tener un valor simbólico, constituyendo algo así como una referencia ancestral, una manifestación de etnicidad que Roma tolera en algunas comunidades de astures y galaicos. En segundo lugar, en algunos castros del Hierro Pleno se podrá entrever alguna vinculación entre piedras hincadas y esculturas zoomorfas ("verracos"), que daría pie a pensar que estas barreras desempeñaban también un papel demostrativo de la comunidad y su fortaleza (Esparza 2003). Por ello, ¿no habría que considerar también algún significado de esta índole en el caso de las piedras hincadas de los castros del Primer Hierro? Como sólo un reducido número de castros cuenta con estas barreras, pudiera suponerse, por ejemplo, que éstos eran especialmente importantes, tal vez en el orden político, pero los pocos datos existentes son contradictorios.

\subsection{El interior de los castros}

En la mayoría de los castros que comentamos, conocidos superficialmente, se desconoce cómo era la arquitectura doméstica. En realidad, durante mucho tiempo apenas se pudo contar sino con la información relativa a Sanchorreja, donde parece haber viviendas de planta rectangular, hechas con mampostería en seco, y de las que apenas se conservan las hiladas inferiores y pavimentos de tierra. Da la impresión de que no existe ese patrón tan definido que más tarde se verá en los grandes castros de Avila, pues si en Sanchorreja parece haber ya algunas viviendas pegadas a la muralla, otras están en zonas centrales. Sin embargo, debe aguardarse hasta la publicación de las diferen- tes campañas realizadas, pues la mayoría de las excavadas en los años treinta deben de corresponder a la ocupación de Cogotas I.

Al multiplicarse los trabajos de excavación, se han ido hallando progresivamente estructuras domésticas, que parecen coincidentes en los castros de unos y otros sectores. Ya hemos citado las cabañas circulares descubiertas en Camarzana, y luego en los castros de Manzanal de Abajo, Moveros y Manganeses, que con las de Benavente, se integran plenamente en la arquitectura del Soto, adecuadamente tratada en el capítulo 2. La misma confirmación se obtiene en Salamanca, en cuyo castro de San Vicente se han exhumado varias casas análogas a las de Ledesma; y si en el sector leonés apenas asomaba una construcción circular en Pedredo, la confirmación del carácter castreño de Sacaojos, con numerosas cabañas superpuestas, ha despejado las dudas.

La información hoy disponible ha sido integrada en un minucioso estudio de conjunto por $M^{a}$ L. Ramírez (1999), que recoge toda su problemática. Retengamos simplemente, para hacernos una idea de cómo era la vivienda castreña, que se trata de cabañas de planta circular, pequeñas —entre 3,5 y $7 \mathrm{~m}$ de diámetro- dotadas a veces de un basamento de piedra. El alzado era de adobes o tapial, aunque en algún caso, al no haberse encontrado vestigios del mismo, se podría suponer que era de ramaje, como debió de serlo también la cubierta, posiblemente cónica. Los detalles constructivos - preparación del pavimento, banco corrido, revestimientos - y aun los decorativos -enlucidos con temas geométricos pintados en coloresnos remiten constantemente al grupo del Soto, como las inhumaciones infantiles en el subsuelo, ahora halladas también en Manganeses, o ciertos depósitos de huesos de fauna (Caro y López 2001).

Estas construcciones parecen contar con un único ambiente en su interior, en el que coexistían el descanso y las actividades culinarias y acaso el hilado. En cambio hay que mencionar, como es lógico, la existencia en el poblado de distintos ambientes fuera de las viviendas, que se atisba en los castros donde se ha excavado mínimamente: aparte de algún horno en el exterior de las casas, o de las zonas de vertedero, se ha creído detectar sectores dedica- 
dos a la metalurgia broncista, por ejemplo en el sector III de Manganeses, o en el sondeo B de Benavente.

De cara a profundizar nuestro conocimiento de las comunidades castreñas, sería imprescindible esclarecer la funcionalidad de los distintos recintos, allí donde los hay, pero sobre todo llegar a delimitar eventuales unidades domésticas de producción, almacenamiento, etc., pero ello no ha sido todavía posible, pues la reducida superficie de las excavaciones no permite comprender el verdadero alcance de las "estructuras anejas" que a menudo se mencionan cerca de las cabañas, o de la integración de dos construcciones en un recinto vallado, como en el castro salmantino. Por ello parece necesario seguir, como guía para avanzar en la investigación, un enfoque tan fructífero como el empleado en los castros prerromanos de $\mathrm{La}$ Cabrera y El Bierzo, donde a partir de la detección de 'unidades de ocupación' se han podido realizar importantes avances en la caracterización socioeconómica de las comunidades y del poblamiento en su conjunto (Fernández Posse et al. 1994).

Mientras tanto, quedémonos al menos con algunos datos obtenidos en el interior de los castros que nos ilustran acerca de las actividades económicas. Molinos manuales, naviformes, nos remiten a la molienda de cereales (han sido hallados trigo y cebada) pero también a la de bellotas; y los restos de fauna que ya se citaron evidencian una cabaña ganadera que encaja bien con lo que la naturaleza ofrecía en los alrededores, en la que sin duda se cazaba también. Algunas veces se han hallado objetos - anzuelo, pesos de red- relacionados con la pesca fluvial, actividad que, como la recolección de almendras y bellotas, o de otros frutos silvestres aún no probados, tendría un valor no pequeño en la alimentación castreña. En el interior de los castros, y tal vez en sectores concretos, como se ha dicho, se hallan fragmentos de crisoles (o vasijas-horno), goterones, escorias, etc., indicativos de una metalurgia broncista sin duda importante; del hierro, en cambio, es muy poco lo que se conoce, aunque en Sejas de Aliste parece haberse dado una temprana forja de este metal.

Los objetos, especialmente los metálicos fíbulas, especialmente de doble resorte, pulseras y broches de cinturón, cuchillos de hierro, etc. - hallados en las excavaciones, nos remiten con facilidad al grupo del Soto, especialmente en su fase de madurez, por lo que pueden integrarse en un proceso general de intercambio, de difusión de piezas y modelos, muchas veces de aire meridional. No es cuestión de volver sobre estos problemas, bien tratados por Romero y Ramírez (1996; vid. Romero et al. 2008), o sobre la importancia del rincón de Ávila-Salamanca en relación con el mundo orientalizante del SO. (González-Tablas 1990; Álvarez-Sanchís 1999: 85-91; Blanco y Fabián 2005; Esparza y Blanco 2008), o sobre su papel en el intercambio socio-político, como bienes de prestigio (Álvarez-Sanchís 2000). Haremos, si acaso, una alusión al papel de estos núcleos castreños en el proceso económico general.

Se trata aparentemente de núcleos que tienden a una modesta autosuficiencia, pero ¿hubo en estos castros algún tipo de complementariedad? Fernández-Posse (1999:153) no cree que hubiese un dualismo entre las comunidades de las zonas serranas y las de las zonas sedimentarias, pues considera que en economías campesinas no se llega a procesos de esa escala, pero algunos materiales encontrados en el interior de los castros parecen exigir mayor discusión. Veamos un caso expresivo, como es el de los revestimientos (enlucidos, estucos, etc.) de las viviendas, pintados en colores. En los casos de Benavente y de Manzanal de Abajo, el colorante rojo empleado no es ocre, sino cinabrio, un sulfuro de mercurio para el que hay que descartar una procedencia local y que debe de venir - mejor que de la zona de Almadén- de los numerosos veneros de la cabecera del Esla, en la montaña cantábrica leonesa. Que tales indicios eran conocidos en el Primer Hierro es cosa probada por el hallazgo de Lois (León), donde al avanzar una mina actual sobre viejas obras se encontró un caldero de chapas de bronce remachadas, similar a los de Sanchorreja, La Mazada, etc. (Armada 2008: 129 ss.). Pues bien, el cinabrio llegó, bajando el valle del Esla, al floreciente poblado benaventino, pero llegaba también $50 \mathrm{kms}$ aguas arriba del Tera, hasta el modesto castro de Manzanal, en la boscosa Carballeda. En el mismo sentido habrá que discutir la presencia de crisoles, moldes, tortas de fundición, etc. en los poblados sotenses de la cuenca sedimentaria: son análogos a los que 
hemos citado en nuestros castros... pero allí no hay, por razones geológicas, minerales de cobre ni de estaño, por lo que no se puede descartar que al menos una parte de los lingotillos o tortas de bronce preparados en los castros occidentales salieran de ellos para abastecer a los otros poblados. Insistamos, pues, en la necesidad de unas excavaciones en extensión orientadas a la búsqueda de las estructuras de producción en las que podrían hallarse las respuestas a tales cuestiones.

\section{4 ¿Un mundo sin muertos?}

Con la excepción de las inhumaciones infantiles bajo las viviendas de Manganeses de la Polvorosa que, como se ha visto, encajan a la perfección en los rasgos del Soto de Medinilla, sorprende grandemente la falta de hallazgos funerarios en los castros que nos ocupan. Dado que dos de los castros abulenses más importantes, los de Las Cogotas y La Mesa de Miranda, tendrán en el siglo IV a.C. importantísimas necrópolis de incineración, estaríamos tentados de extrapolar ese hecho a los restantes castros, incluyendo éstos más antiguos; sin embargo, parece más prudente esperar hasta que la intensificación de los trabajos de campo, la mejora en los procedimientos de prospección tecnificada, o simplemente la casualidad, terminen proporcionando alguna evidencia al respecto. Mientras tanto - confiemos en que no haya de pasar un siglo, como ha sucedido con la necrópolis de Numanciadeberán tenerse en cuenta únicamente algunas informaciones problemáticas, de las que se podría desprender incluso la inexistencia de rituales funerarios durante los siglos que estudiamos.

Es verdad que en las inmediaciones de algunos castros — pensemos en el sitio de Las Paredejas, dentro del conjunto del Berrueco, o en el Picón de la Mora- han aparecido materiales que por sus características, más concretamente por la abundancia de objetos metálicos, han llevado a sospechar que pudieran corresponder a sectores funerarios, acaso de incineración por no haberse hallado esqueletos humanos. Sin embargo, no hay más argumentos que avalen la interpretación funeraria, por lo que ha prevalecido la consideración de estos sitios como poblados (p.e. Martín Valls 1999: 179).

Mucho más importante es lo observado en Sanchorreja (González-Tablas 1990 y 2005) donde hace pocos años se excavó en el denominado sector necrópolis, situado extramuros, a unos trescientos metros antes de llegar al lienzo que cierra la muralla por el SO. Allí se hallaron una serie de hoyos, de hasta un metro de profundidad, con un relleno de aspecto ceniciento que encerraba fragmentos cerámicos - con decoración a peine, algunos de importación meridional, y también algunos de Cogotas I cuya presencia se debería simplemente a la remoción del terreno- y sobre todo trozos de objetos broncíneos, entre los que hay asas $\mathrm{y}$ apliques de recipientes rituales, colgantes, varillas y sobre todo chapas que en unos casos corresponden a calderos y en otros deben de ser apliques, tal vez de muebles, habiendo también algún pasador de hierro (Fig. 16). La cronología de los materiales apunta a los siglos VIII-V a.C., siendo muchos de ellos relacionables con el ámbito orientalizante, aunque se sugiere que algunos de ellos pueden haber sido manufacturas locales. Para estos conjuntos se propone que se trata de depósitos de carácter funerario.

Además de los mencionados hoyos, se excavó también una estructura tumular hecha de grandes bloques de piedra, junto a la cual había una especie de cámara con una fosa en la que se realizó fuego y se recubrió luego con adobes y tierra compactada. Sobre los adobes había cerámica a peine e importada, un cuchillo y un escoplo de hierro y algunos fragmentos de bronce correspondientes a fíbulas y a un asa de recipiente, además de algunos huesos de fauna.

A la vista de las características de las estructuras, de la fragmentación de los objetos, de la utilización del fuego, se propone su correspondencia a un ritual funerario en el que no se han conservado los restos humanos, de los cuales procedería sin embargo un elevadísimo porcentaje de fósforo. Estaríamos, pues, ante un complejo ceremonial que abarcaba la realización de piras, la deposición de cenizas y materiales afectados por el fuego, y la colocación de objetos en una especie de altar que luego quedó oculto, aunque marcado por el túmulo visible exteriormente. 

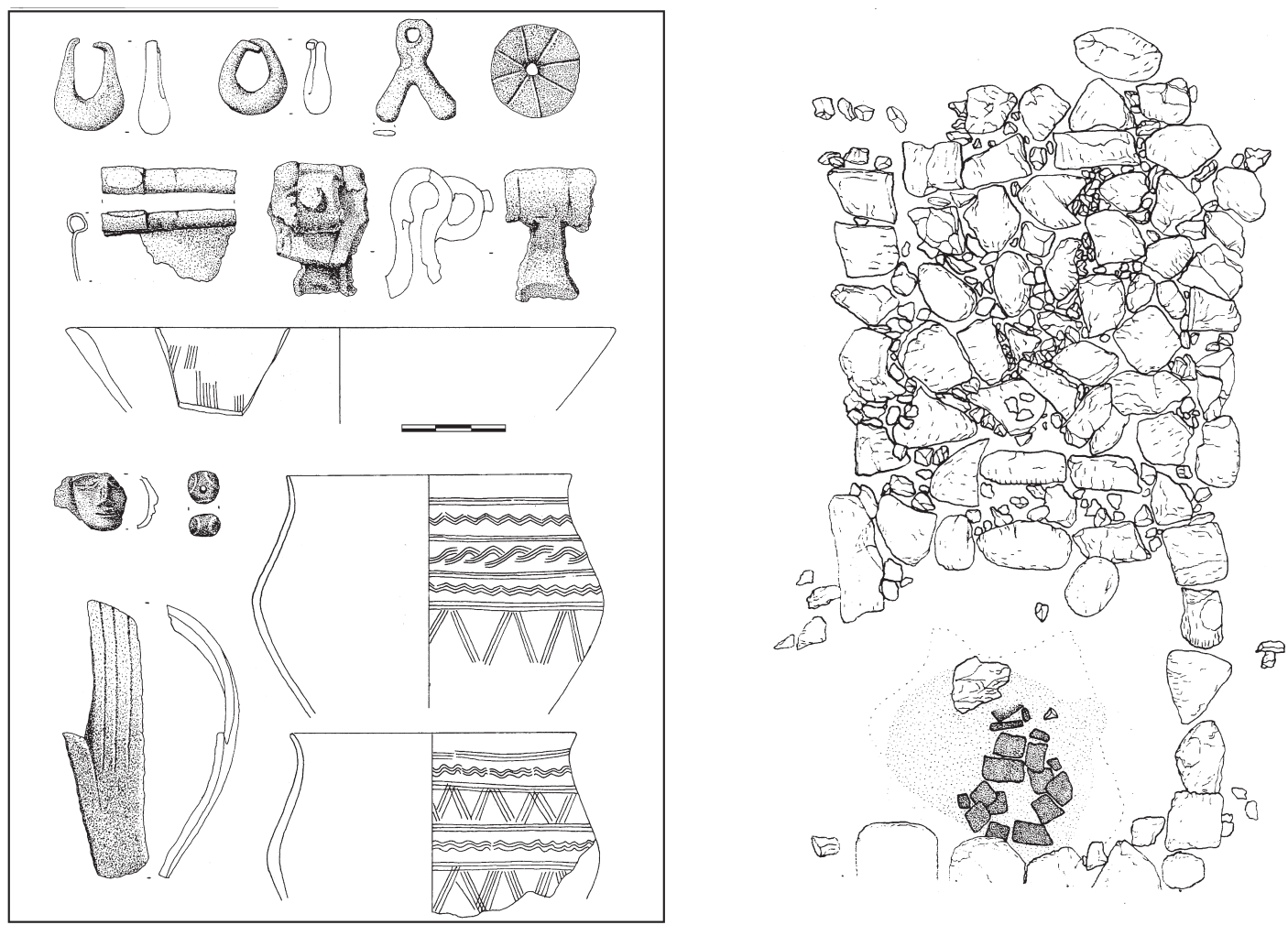

Figura 16.- Estructura hallada en el "sector necrópolis" de Sanchorreja, y selección de materiales de este sector (basado en González-Tablas 1990).

La interpretación de tales vestigios como necrópolis no ha encontrado mucho eco en la bibliografía, seguramente porque la importancia de las conclusiones que se derivarían hace especialmente necesario conocer los detalles más precisos de todas las estructuras excavadas, de la posición de los objetos y de los análisis realizados. Eso sí, aun rechazando que los hallazgos autoricen a relacionar el lugar con una necrópolis en sentido estricto, se admite su pertenencia a ceremonias o ritos de significación imprecisa, banquetes de carne tal vez (Delibes et al. 1992-93: 425-426; Delibes et al. 1999: 109), ligados a aristocracias guerreras (Álvarez-Sanchís 1999: 96).

En cualquier caso, estamos ante una situación excepcional, que no parece tener parangón en ningún otro yacimiento. Por eso, ante ausencia tan reiterada de restos funerarios, deben considerarse otras posibilidades, por inusuales que parezcan. Así, la de que se practicasen unos ritos funerarios que no conservaban el cadáver - exposición a los buitres, arrojamiento a las aguas, cremación y aventamiento de las cenizas, etc.- y de los que difícilmente podríamos llegar a tener pruebas; sin descartar tampoco la de que, simple y llanamente, no enterrasen a sus muertos: ésta podría ser la interpretación correcta de algunos discutibles hallazgos como los de "calaveras" en El Castro de Sacaojos, de una mandíbula de adulto en La Corona de Manganeses, de un par de dientes del castro de San Vicente, o de tres piezas dentarias, una mandíbula infantil y un fémur femenino encontrados en el sector A del castro de Benavente. Para estos restos caben ciertamente explicaciones muy diversas (Celis 1993: 129-130; Esparza 1995: 135; Delibes et al. 1995: 77), pero también la que formularemos como última propuesta.

En efecto, tal vez debamos reorientar las búsquedas en otro sentido, porque deslumbrados por la idea de unas necrópolis, tumulares o de tumbas marcadas por estelas, emplazadas en las cercanías de los poblados, etc., seguramente hemos dejado pasar otras posibilidades, como la de que los restos humanos se hallen en los propios castros, aunque no en las estructuras de habitación que siempre centran la atención de 
los excavadores. Si, en la línea de Champion (1982), se considera que la muralla expresa materialmente la apropiación del territorio, ¿no habría que aprovechar la experiencia británica y pensar también en la vinculación de los restos fúnebres con ritos de fertilidad de la tierra? Allí, en los hillforts y otros recintos de la Edad del Hierro se han ido descubriendo una y otra vez huesos humanos - esqueletos completos, cráneos, miembros articulados, huesos sueltosaparentemente entre basura, sin enterrar, o bien en hoyos o en los propios fosos (Hill 1995). En nuestros castros, en cambio, nunca se ha considerado prioritaria la excavación de los fosos, donde podría haber alguna sorpresa, y tampoco se habían encontrado hoyos, que ya han comenzado a aparecer, por ejemplo en Sacaojos. Desde luego, no deja de ser inquietante el que los mencionados restos humanos de Benavente hayan salido, frente a toneladas de material repartido en más de $100 \mathrm{~m}^{2}$ de excavación, en un pequeñísimo sector marginal del poblado, de unos $5 \mathrm{~m}^{2}$, y probablemente sólo en la primera de las nueve fases de ocupación.

Así pues, un panorama oscuro, pero prometedor, caracteriza lo relativo a la esfera de los ritos, que no afectaría sólo a los muertos, a juzgar por otros indicios: antes se aludió a los banquetes de carne, probablemente ceremonias de índole sociopolítica (Armada 2008), y a ellos podrían vincularse algunas piezas halladas en castros, como los restos de calderos de Sanchorreja y La Mazada; además, la deposición en ríos, lagunas, etc. de otros bronces, como las mencionadas lanzas de Bembibre, que vendrían a dar testimonio de un culto a las aguas fuertemente arraigado en el cuadrante noroeste (Delibes et. al. 1999: 175 y 183).

\section{La aparición del fenómeno castreño, un fe- nómeno controvertido}

Recordemos el contraste que se ha venido observando en el poblamiento - y en tantas otras cosas - del grupo Soto respecto al de Cogotas I. De ese contraste, debe hacerse hincapié en un aspecto, el que muestra un hábitat sin duda estable frente al anterior, donde predominaba otro menos duradero, aun cuando hubiese sitios excepcionales.
Desde luego, por lo que respecta a los castros del Oeste, la impresión que se obtiene no puede ser más nítida, aunque aquí debe expresarse de otra manera: dada la rareza extrema que en estas zonas tienen los yacimientos de Cogotas I, poco puede afirmarse acerca de la permanencia o no de sus poblados, ya que resultan "invisibles", y por ello, si es que existieron, cabría sospechar su sencillez. Por contra, los castros, más allá de constituir aldeas estables, representan un hábitat que pretende claramente hacerse ver. La exhibición de esfuerzo colectivo que hay en la arquitectura castreña nos indica, dejando aparte su valor disuasorio frente a alguna agresión, una actitud mental nueva. Ésta podría ciertamente haber sido precedida por el surgimiento, durante los tiempos más avanzados de la Edad del Bronce, de poblados emplazados en elevaciones con gran control visual sobre el territorio y, a su vez, visibles desde muy lejos; pero lo importante es que ahora vamos a asistir a una eclosión de pequeñas aldeas fortificadas, cerradas sobre sí mismas, que, a modo de hitos, jalonan un paisaje netamente humanizado, un paisaje fortificado, al decir de F. Criado (1993).

Esta reiterada autoafirmación de cada comunidad no es el único rasgo perceptible de la mentalidad de la época, pues se acaba de aludir a rituales nuevos, como los de consumo de carne, o los relacionables con la muerte, donde destaca alguna novedad, por ejemplo la separación de los niños con respecto a los adultos, hoy por hoy invisibles... No sería difícil poner en relación esta nueva forma de entender el mundo con modificaciones infraestructurales, como una progresiva mutación del medio al compás del clima Subatlántico; o el propio proceso de concentración de poblaciones y de economía más intensiva que venía ya dándose, etc., aunque todavía es pronto para adentrarnos en tan atractivos problemas.

Lo cierto es que estamos ante un fenómeno novedoso, cualitativa y cuantitativamente, sobre el que se ha empezado a discutir. En un atractivo libro, Fernández-Posse (1999) ha pasado revista al debate, de mayor alcance, de la continuidad o ruptura entre Cogotas I y el Soto, entre Bronce e Hierro, y más recientemente se ha formulado una propuesta de tipo más global acerca de los cambios producidos a escala peninsular en las estrategias de subsistencia, que de alguna forma 
nos atañe. Burillo y Ortega (1999) sostienen la existencia de una profunda crisis - demográfica y socioeconómica - en el Bronce Tardío, siglos XIV al XI a.C. aproximadamente. Una respuesta a la crisis se habría dado en el valle del Ebro, donde aparece un nuevo modelo de asentamiento a base de poblados estables que repiten un modelo muy estandarizado (el "modelo de calle central" que se ha visto en otros capítulos de este libro), mientras que en la zona duriense, no afectada por dicha crisis, se habría pasado gradualmente desde los núcleos de Cogotas I a los poblados con cabañas circulares de postes que a su vez dieron paso a las casas circulares de adobe o tapial, siendo las mismas comunidades cogotenses las que se transformaron en las del Soto. Sin entrar aquí en el fondo de la propuesta, sí debe señalarse que, en algunos aspectos al menos, tropieza con un obstáculo que hoy no es fácil de franquear, el de la frágil documentación en la que se basa. En efecto, tal propuesta acepta las conclusiones aportadas por otros investigadores, como Álvarez-Sanchís para el caso del SE de la Meseta y de Misiego et al. para el castro de Sacaojos, conclusiones que no parecen, hoy por hoy, suficientemente firmes. Veámoslo con un poco de detenimiento, pues afectan a los castros del Oeste:

En el caso de Sacaojos, la excavación ha documentado la superposición de tres fases de ocupación: dejando de lado una posible fase calcolítica, hay un "campo de hoyos" de la plenitud de Cogotas I, sobre la que se construyó un poblado de chozas circulares de ramaje con postes de madera, atribuida al Soto Formativo, y posteriormente un poblado del Soto Pleno, protegido, como vimos, por una muralla de tapial. Los excavadores concluyen afirmando "...creemos que no hay hiato entre la primera ocupación y la asociada a las chozas circulares" (Misiego et al 1999: 63), pero una y otra fases quedan fechadas por los mismos autores entre los siglos XIIIXI a.C. y IX-VIII a.C. respectivamente, es decir con una separación de un siglo como mínimo.

El rincón suroccidental de la meseta analizado por Álvarez-Sanchís (1999) presenta una enorme dificultad, pues los yacimientos son conocidos de forma somerísima, lo que permite que se hagan interpretaciones contrapuestas, sin duda provisionales. Afirma este investigador que la continuidad entre Bronce Final y Primer
Hierro "parece fuera de toda duda", y que sobre esa base se produce una dualidad de territorios que opone el de orientación agrícola y otro preferentemente ganadero de las zonas montañosas del SE, esto es, entre el patrón de asentamiento tipo Soto y el asentamiento castreño (Ibid.: 98-100). Esta argumentación, que resulta fundamental para explicar la ulterior formación de los vettones históricos, puede ser cuestionada: si, dejando a un lado la Alta Extremadura, pasamos revista a los 8 yacimientos que forman la aureola "protovettona" de su mapa 28, tan expresivo, hallamos que algunos de ellos son del Soto (sin duda Las Zorreras, probablemente Herguijuela), y en otros cabe discutir alguna vinculación (Colmenar de Montemayor y Las Paredejas), por lo que apenas nos quedan Las Cogotas, Ulaca y Sanchorreja. Si en éste ultimo, como vimos, se puede discutir sobre la coexistencia de las cerámicas de Cogotas I con las pintadas meridionales, no puede decirse lo mismo de los restantes, especialmente de Las Cogotas donde no hay prueba alguna de la continuidad de ocupación. Por ello, aunque sea convincente la hipótesis de una reorganización general del poblamiento, en relación con el intercambio de bienes de prestigio, lo cierto es que los datos son endebles, más válidos para algún yacimiento concreto que para explicar el fenómeno castreño.

Es necesario, pues, esperar antes de alcanzar una conclusión, que en estos momentos parece más bien negativa. Saque el lector su propia conclusión de los datos de León, por ejemplo: por razones de acceso a la bibliografía (Abarquero Moras 1997; Celis Sánchez 1996; 2002; Misiego et al. 1999; Rodríguez Marcos et al. 1999), vamos a referirnos al marco estrictamente provincial, donde se encierran 40 yacimientos del Soto frente a 8 de Cogotas I. La coincidencia de materiales parece que sólo puede afirmarse en Sacaojos (pero sin continuidad, como ya se dijo), en Valencia de Don Juan (al menos salen cerámicas de una y otra clase entre los rellenos que colmatan el foso del castillo medieval) y en Ardón. Únicamente en Ardón, a orillas del Esla, parece estar representado el momento más evolucionado de Cogotas I, el que podría permitir el enlace..., pero en este yacimiento, como en la mencionada fortaleza, lo que se ha descubierto hasta ahora corresponde al Soto Pleno, y no al 
Inicial, de manera que sigue sin haber pruebas de la pretendida continuidad. En cualquier caso, ni uno solo de los castros más a poniente, hacia los Montes de León parece enraizado en aquella cultura del Bronce Medio y Tardío, y hoy se entienden mejor en relación con los poblados sotenses de las zonas más orientales, en los que van identificando defensas terreras y fosos.

Utilizando otro marco artificial, la provincia de Zamora, las cifras que manejamos hasta el momento en nuestro estudio de conjunto resultarían igualmente elocuentes: frente a 78 yacimientos del Primer Hierro, el punto de partida serían aquí 50 yacimientos cogotenses (muchos de ellos del momento más antiguo), pero con una distribución totalmente disimétrica, ya que los de Cogotas I apenas se dan en las zonas occidentales. En cuanto a superposición, sólo cabe contar 5 casos, todos ellos difíciles de valorar estrictamente, pues en algun caso hay demasiada distancia cronológica entre las dos ocupaciones (caso de Ricobayo), o porque no es posible ir muy lejos, dada la naturaleza de los datos: esta sería la situación de la capital zamorana, donde - como ha sucedido también en la salmantina, o en Ledesma- escasos fragmentos de Cogotas I salen en los niveles de base, que probablemente indican más que una continuidad, una simple presencia anterior, cosa lógica a tenor del magnífico emplazamiento de esos tres lugares. Otro dato interesante a tener en cuenta es la clara diferenciación que en algunas localidades ofrecen dos yacimientos relativamente próximos correspondientes a las fases cuya continuidad se busca: en Pinilla de Toro (Zamora), o en Martinamor (Salamanca), el divorcio es bien expresivo.

Por todo ello, aunque se acepte - como sostiene Fernández-Posse (1999: 140)— que Cogotas I no se extinguió, sino que algunos yacimientos de esa cultura, como Sanchorreja, tomaron parte en el proceso de cambio, cuesta mucho trabajo admitir que los castros del Oeste puedan ser justificados recurriendo sin más a un sustrato indígena cogotense.

Recientes hallazgos, producidos hasta ahora en zonas al sur del Duero, vienen a enriquecer el debate. Basándose en prospecciones de cierta intensidad realizadas para el Inventario Arqueológico de Valladolid, Quintana y Cruz (1996) han dado a conocer un nutrido conjun- to de yacimientos del Soto Inicial, en algunos casos coincidentes con los de Cogotas I, para los que han propuesto una interpretación continuista. Por su parte, Fabián (1999) presenta una serie de yacimientos similares descubiertos en el Inventario de Ávila, algunos de los cuales están muy cerca de los controvertidos castros abulenses de Sanchorreja, Las Cogotas, etc., y subvierten por completo el análisis (espacial, etc.) realizado hasta ahora: Álvarez-Sanchís manejaba 3 yacimientos de Cogotas I y sólo uno del Soto, y ahora pasarían a ser 5 y 8 , respectivamente, con sólo 2 casos de superposición.

La interpretación de estas novedades es todavía incierta - entre otras cosas porque, al tratarse de hallazgos superficiales, no es muy precisa su definición arqueológica, y nada seguro el establecimiento de momentos transicionales respecto a Cogotas I y al Soto Pleno- pero tales yacimientos son ya una realidad de innegable trascendencia: estos pobladitos del Soto Formativo, en los que uno se arriesgaría a sospechar una vinculación con la minería del cobre y la metalurgia broncista, ¿no serán el imprescindible punto de partida para explicar la aparición de los castros abulenses? Es precisamente esta entidad arqueológica sotense - relacionable sin duda con otras áreas peninsulares, el valle del Tajo, sin ir más lejos-, y no Cogotas I, la que parece proporcionar la base humana para el cambio en el poblamiento.

Este de la demografía (véase Álvarez-Sanchís y Ruiz Zapatero 2001) es un problema importante a la hora de afrontar el proceso de cambio que nos ocupa, pues el elevado número de castros observado sólo podría justificarse, mediante segmentación - esto es, la duplicación producida por la salida de un grupo de pobladores del castro para fundar uno nuevo- si se hubiesen dado tasas de crecimiento anual muy elevadas, del orden del $1 \%$, inconveniente que ya nos llevó (Esparza 1995: 142-142) a no descartar la existencia de alguna aportación humana exterior, como bien ha explorado recientemente Antonio Blanco (2010a y 2010c). Las cosas serían más sencillas si, como indican esos datos novedosos, se va desvelando un poblamiento correspondiente al Soto Inicial; de ahí que resulten tan interesantes yacimientos de esa fase, como los castros de Sacaojos y Benavente, y especialmente algunos muy al oeste, en ple- 
no Aliste, como el de La Mazada y tal vez el yacimiento - no castreño, sino completamente abierto - de El Villar, en Samir de los Caños.

Ese castro de La Mazada presenta un interés añadido, pues viene a matizar una impresión que podría haberse deslizado en este capítulo, la de que estos castros occidentales corresponden a una expansión de la cultura del Soto desde el centro de la cuenca, aquella proyección hacia el NO. que hace mucho señalara Palol. El estudio de los materiales metálicos hallado en él nos ha llevado a proponer (Esparza y Larrazábal 2000) que, ya desde el siglo VIII a.C., debió de jugar un papel importante en los procesos de intercambio, posiblemente en relación con la fachada atlántica, y la posible contribución de estos yacimientos a la fase de madurez del Soto. De ser así, los castros no serían el resultado más bien tardío de un proceso de difusión -meros receptores de lo que llegaba desde el centro de la Cuenca-, sino que habrían participado activamente en la propia constitución del grupo del Soto.

Sea cual sea el carácter de la población que impulsó el fenómeno castreño, parece posible concluir con una caracterización general del mismo. Por encima de las divergencias que nos separan en cuanto a argumentos concretos, creemos aceptable la consideración que Fernández-Posse, Álvarez-Sanchís o Burillo y Ortega hacen acerca de los castros en relación con nuevas formas socioeconómicas: frente a un territorio continuo en el que anteriormente se asentaban grupos relativamente flexibles, en la primera mitad del ler milenio a. C. se asistirá a la fijación de las comunidades a múltiples espacios fragmentarios, nucleados por los castros. Álvarez-Sanchís (1999 y 2000), desde una visión "centro/periferia" de la protohistoria del occidente peninsular, pone el acento en el papel de los nuevos poblados del borde SE. en el proceso de intercambio de bienes de prestigio, considerando incluso el nacimiento de incipientes estructuras territoriales, unos territorios medianos, con un castro y otros pequeños establecimientos subsidiarios. Si algunos castros concretos, como Los Castillejos o La Mazada, podrían apoyar esa interpretación, una consideración del conjunto de nuestros castros occidentales parece ir más bien en el sentido de las pequeñas comunidades poco jerarquizadas, de modesta economía tendente a la autosuficiencia, fuertemente vinculadas al territorio circundante en el que está prácticamente todo lo que necesitan, y en el que se afirman visualmente mediante los poderosos cierres pétreos. Estaríamos, en definitiva, ante el enfoque de los castros como aldeas campesinas que últimamente se apunta (Fernández-Posse et al. 1998; Fernández-Posse 1999: 266-268) como prometedora línea de investigación y, por otro lado, como primeras manifestaciones de un asentamiento permanente que trunca la trayectoria de los efímeros establecimientos de las gentes de finales de la Edad del Bronce (Blanco 2011).

\section{REFERENCIAS BIBLIOGRÁFICAS}

Abarquero Moras, F. J. (1997): Área nuclear y territorios de expansión. La proyección de Cogotas I por las regiones periféricas de la Península Ibérica. Tesis doctoral defendida en la Universidad de Valladolid.

Abarquero Moras, F. J. (2005): Cogotas I. La difusión de un tipo cerámico durante la Edad del Bronce. Arqueología en Castilla y León, Monografías 4, Junta de Castilla y León, Valladolid.

Alario, C.; Macarro, C. (2007): La ciudad hispano-romana de Salmantica a partir de la secuencia estratigráfica del solar del Trilingüe. Arqueología en la Vía de la Plata (Salamanca) (G. Gillani, M. Santonja, eds.), Ediciones de la Fundación Premysa, Colección gentes y paisajes, Salamanca.

Almagro-Gorbea, M. (1994): Urbanismo de la Hispania "céltica. Castros y Oppida del centro y occidente de la Península Ibérica. Castros y Oppida en Extremadura (M. Almagro-Gorbea, A. Mª Martín, eds.), Complutum Extra, 4, Madrid: 13-75.

Alonso Martínez, N.; Junyent, E.; Lafuente, A.; López Melción, J.B. (1998): Poder, símbolo y territorio: el caso de la fortaleza de Arbeca. Actas del Congreso internacional Los Iberos. Príncipes de Occidente. Estructuras de poder en la sociedad Ibérica. Fundación "La Caixa", Barcelona. 
Álvarez GonZÁlez, Y. (1993): Arqueología del paisaje: modelos de ocupación y explotación de los castros del valle de Noceda (León). Complutum, 4: 265-278

Álvarez-Sanchís, J. R. (1999): Los Vettones. Bibliotheca Archaeologica Hispana, 1, Real Academia de la Historia, Madrid.

Álvarez-Sanchís, J. R. (2000): The Iron Age in Western Spain (800 BC- AD 50): an overview. Oxford Journal of Archaeology, 19 (1): 65-89.

Álvarez-Sanchís, J. R. (2007): El poblado fortificado de La Mesa de Miranda (Chamartín, Ávila) y su relación con el poblamiento prerromano del valle Amblés. Paisajes fortificados de la Edad del Hierro. Las murallas protohistóricas de la Meseta y la vertiente atlántica en su contexto europeo (L. BerrocalRangel, P. Moret, eds.), Bibliotheca Archaeologica Hispana, 28, Real Academia de la Historia-Casa de Velázquez, Madrid: 237-254.

Álvarez-Sanchís, J. R.; Ruiz Zapatero, G. (2001): Cementerios y asentamientos: bases para una demografía arqueológica de la Meseta en la Edad del Hierro. Entre Celtas e Iberos. Las poblaciones protohistóricas de las Galias e Hispania (L. Berrocal-Rangel, Ph. Gardes, eds.), Bibliotheca Archaeologica Hispana, 8, Real Academia de la Historia, Madrid: 61-75.

Álvarez-Sanchís, J. R.; Ruiz Zapatero, G.; Lorrio, A.; Benito-López, J. E.; Alonso Hernández, P. (1998): Las Cogotas: anatomía de un oppidum vettón. Homenaje a Sonsoles Paradinas (M. Mariné, E. Terés, coords.), Múseo de Ávila: 73-94.

Andrade Olalla, A.; Ruiz Zapata, M.B.; Gil García, M.J.; Fombella Blanco, M. A.(1996): Acción antrópica y su impacto sobre la vegetación, desde el tránsito subatlántico-subboreal, en la vertiente norte de la Sierra de Gredos (Ávila, España). Estudio palinológico. Estudios palinológicos. XI SImposio de Palinología (A.P.L.E) (B. Ruiz Zapata, ed.), Alcalá de Henares: 7-12.

Arizaga Bolumburu (1990): Urbanistica medieval (Guipuzcoa). San Sebastián.

Armada, X.-L. (2008): ¿Carne, drogas o alcohol? Calderos y banquetes en el Bronce Final de la Península Ibérica. Cuadernos de Prehistoria y Arqueología de la Universidad de Granada, 18: 125-162.

Benet, N. (1990): Un vaso pintado y tres dataciones de C-14 procedentes del Cerro de San Pelayo (Martínamor, Salamanca). Numantia, III: 77-94.

Benet, N.; JimÉnEz, M.C. y Rodríguez, Ma B. (1991): Arqueología en Ledesma, una primera aproximación: La excavación den la Plaza de San Martín. Del Paleolitico a la Historia (M. Santonja, coord.), Salamanca: 117-136.

Benet, N.; LóPez JimÉnez, O. (2008): Investigaciones recientes en la Edad del Hierro en Salamanca y la Beira Alta: los castros del occidente. Arqueología Vettona. La Meseta Occidental en la Edad del Hierro (J. Álvarez-Sanchís, ed.), Zona Arqueológica, 12, Museo Arqueológico Regional, Alcalá de Henares: $162-181$.

Blanco González, A. (2008): Tendencias del uso del suelo en el Valle Amblés (Ávila, España). Del Neolítico al Hierro Inicial. Zephyrus, LXII (julio-diciembre): 101-123.

Blanco GonzÁlez, A. (2010a): ¿Nuevos hogares para los emigrantes? Casas y paisajes en el debate sobre el límite entre Cogotas I y el Primer Hierro en el Valle del Duero. Zephyrus, LXVI (julio-diciembre): 155-179.

Blanco GonzÁlez, A. (2010b): La definición del Hierro Antiguo en el castro de Las Cogotas (Cardeñosa, Ávila). Consideraciones sobre algunos materiales del Museo Arqueológico Nacional. Complutum, 21 (1): 123-143.

Blanco GonzÁlez, A. (2010c): 'Arqueología de la población' entre la Edad del Bronce y el Primer Hierro (1800-400 AC): sobre procesos migratorios y colonizadores en la Submeseta Norte. Arqueología de la Población, Arqueología Espacial, 28: 361-379.

Blanco-GonzÁlez, A. (2011): From huts to 'the house': the shift in perceiving home between the Bronze Age and the Early Iron Age in central Iberia (Spain). Oxford Journal of Archaeology, 30 (4): 393-41.

Blanco GonZÁlez, A.; Fabián, F. (2005): Los orígenes de las comunidades castreñas en el suroeste de la Meseta española: el proceso histórico Bronce Final-Segunda Edad del Hierro. Castro, um lugar para habitar. Colóquio Monte Mozinho 2004 (T. Pires, coord.), Cadernos do Museo, 11, Penafiel: 41-53. 
Burillo Mozota, F.; Ortega Ortega, J. M. (1999): El proceso de formación de las comunidades campesinas en el Sistema Ibérico (1400-400): Algunas consideraciones acerca del concepto de «ruptura». El origen del mundo celtibérico. Actas de los Encuentros sobre el origen del mundo celtibérico (J. A. Arenas, Mª. V. Palacios, coords.), Molina de Aragón: 123-141.

Campano Lorenzo, A.; Val Recio, J. Del (1986): Un enclave de la primera Edad del Hierro en Zamora: «El Castro», Camarzana de Tera. Revista de Arqueología, 66: 29-33.

Caro Dobón, L.; López Martínez, B. (2001): Estudio antropológico de las inhumaciones del poblado de la Edad del Hierro "La Corona / El Pesadero" (Manganeses de la Polvorosa, Zamora). Anuario del Instituto de Estudios Zamoranos Florián de Ocampo, 18: 13-23.

Celis Sánchez, J. (1993): La secuencia del poblado de la Primera Edad del Hierro de "Los Cuestos de la Estación", Benavente (Zamora). Arqueología Vaccea. Estudios sobre el mundo prerromano en la Cuenca Media del Duero (F. Romero Carnicero, C. Sanz Mínguez, Z. Escudero Navarro, eds.), Valladolid: 93-132.

Celis Sánchez, J. (1996): Origen, desarrollo y cambio en la Edad de Hierro de las tierras leonesas. Arqueoleón. Historia de León a través de la arqueología, León: 41-67.

Celis SÁnchez, J. (2002): El Bronce Final y la primera Edad del Hierro en el noroeste de la Meseta. Los poblados fortificados del Noroeste de la Península Ibérica: Formación y desarrollo de la Cultura Castreña (M. A. de Blas, A. Villa, eds.), Navia, 97-125.

CHAMPION, T. (1982): Fortification, ranking and subsistence. Ranking, resource and exchange: aspects of the archaeology of early European society (C. Renfrew, S. Shennan, eds.): 61-66.

Conde Moreno, J. F.; Reina Pereda, P. y Silvestre Barrio, M. (1996): El Cerro del Berrueco (Salamanca). Nuevas propuestas para un problema olvidado. Boletín de la Asociación Española de Amigos de la Arqueología, 36: 47-7.

Criado Boado, F. (1993): Límites y posibilidades de la arqueología del paisaje. Spal, 2: 9-55.

De Carlos Izquierdo, J. I. (1992): La Arqueogeografia (Un procedimiento para el estudio del espacio prehistórico). Col. Tesis Doctorales Universidad Complutense, 58/92, Madrid.

Delibes de Castro, G., (1995): Ávila. Del Neolítico al Bronce. Historia de Ávila I. Prehistoria e Historia Antigua (M. Mariné, coord), Ávila: 23-90.

Delibes de Castro, G.; Fernandez Manzano, J.; Celis Sanchez, J. (1992-93): Nuevos "ganchos de carne" protohistóricos de la Península Ibérica. Tabona, VIII (2): 417-434.

Delibes de Castro, G.; Romero Carnicero, F.; Sanz Mínguez, C.; Escudero Navarro, Z.; San Miguel Mate, L. C. (1995): Panorama arqueológico de la Edad del Hierro en el Duero medio. Arqueología y medio ambiente. El primer milenio a.C. en el Duero medio (G. Delibes, F. Romero, A. Morales, eds.), Valladolid: 49-146.

Delibes de Castro; Fernández Manzano, J.; Fontaneda Pérez, E.; Rovira Llorens, S. (1999): Metalurgia de la Edad del Bronce en el piedemonte meridional de la Cordillera Cantábrica. La Colección Fontaneda. Arqueología en Castilla y León, 3, Valladolid.

Escribano Velasco, C. (1990): Contribución al estudio de la Edad del Hierro en el occidente de Zamora y su relación con el horizonte del Soto de Medinilla: "El Castillo", Manzanal de Abajo (Zamora). Anuario 1990, Instituto de Estudios Zamoranos Florián de Ocampo, Zamora: 211-263.

Esparza Arroyo, A. (1986): Los castros de la Edad del Hierro del noroeste de Zamora. Instituto de Estudios Zamoranos Florián de Ocampo, Zamora.

Esparza Arroyo, A. (1990): La Edad del Hierro. Primer Congreso de Historia de Zamora. II Prehistoria e Historia Antigua, Zamora: 101-126.

Esparza Arroyo, A. (1995) La Primera Edad del Hierro. Historia de Zamora. Tomo I. De los orígenes al final del Medievo, Zamora: 102-149.

Esparza Arroyo, A. (e.p.): Spanish hillforts with piedras hincadas. The Western Stone Forts Project (C. Cotter, ed.), Discovery Programme Monologue, Dublin.

Esparza Arroyo, A. (2003): Castros con piedras hincadas del oeste de la Meseta y sus aledaños. Chevaux de frise i fortificació en la primera edat del ferro europea (N. Alonso, E. Junyent, A. Lafuente, J.B. López, coords.), Lleida: 155-178. 
Esparza Arroyo, A. (2009): El significado de los castros del noroeste zamorano. Actas III y IV Congreso de Antropología, Instituto de Estudios Zamoranos 'Florián de Ocampo', Zamora: 29-37.

Esparza Arroyo, A.; Blanco González, A. (2008): El solar de Vettonia, antes de los vettones. Arqueología Vettona. La Meseta Occidental en la Edad del Hierro (J. Álvarez-Sanchís, ed.), Zona Arqueológica, 12, Museo Arqueológico Regional, Alcalá de Henares: 214-231.

Esparza Arroyo, A.; González Gómez, F.; Lucio Martínez, O. R. (1999): El Inventario Arqueológico de la Provincia de Zamora (1991-1995): avance de resultados. II Congreso de Arqueología Peninsular. Tomo III - Primer Milenio y Metodología (R. Balbín Behrmann, P. Bueno Rodríguez, eds.): Zamora: 603-617.

Esparza Arroyo, A.; Larrazabal Galarza, J. (2000): El castro de La Mazada (Zamora): elementos metálicos y contexto peninsular. Actas do $3^{\circ}$ Congresso de Arqueologia Peninsular (Vila Real 21-27 Setembro 1999) (V. Oliveira Jorge, coord), vol 5, Vila Real: 433-476.

FABIÁN GarcíA, J. F. (1986-87): El Bronce Final y la Edad del Hierro en "El Cerro del Berrueco" (ÁvilaSalamanca). Actas del Coloquio Internacional sobre la Edad del Hierro en la Meseta Norte, Zephyrvs, XXXIX-XL: 273-287.

FABiÁn García, J. F. (1999): La transición del Bronce Final al Hierro I en el sur de la Meseta Norte. Nuevos datos para su sistematización. Trabajos de Prehistoria, 56.2: 161-180.

Fabián García, J. F. (2005a): Castro de Las Paredejas (Medinilla, Ávila). Cuadernos de Patrimonio Abulense, 7, Institución Gran Duque de Alba, Ávila.

Fabián García, J. F. (2005b): Castro de La Mesa de Miranda. Chamartín, Ávila. Cuadernos de Patrimonio Abulense, 2, Institución Gran Duque de Alba, Ávila.

Fernández Gómez, F. (1986): Excavaciones Arqueológicas en El Raso de Candeleda (I-II). Institución "Gran Duque de Alba", Ávila.

FernÁNDEZ Gómez (1997): La Necrópolis de la Edad del Hierro de "El Raso" (Candeleda. Ávila). "Las Guijas, B". Arqueología en Castilla y León, Memorias, 4, Valladolid.

Fernández Gómez, F. (2008): Anatomía de un castro vettón. El Raso de Candeleda. Arqueología Vettona. La Meseta occidental en la Edad del Hierro (J. Álvarez-Sanchís, ed.), Zona Arqueológica, 12, Museo Arqueológico Regional, Alcalá de Henares: 182-200.

Fernández-Posse, Ma D (1998): La investigación protohistórica en la Meseta y Galicia. Síntesis, Madrid.

Fernández-Posse, Ma D.y Sánchez-Palencia, F. (1988): La Corona y el Castro de Corporales. II. Campaña de 1983 y Prospecciones en la Cabrera y la Valdería (León). Excavaciones Arqueológicas en España, 153, Madrid.

FernÁndeZ-Posse, Ma D.y Sánchez-Palencia, F. (1998): Las comunidades campesinas en la cultura castreña. Trabajos de Prehistoria, 55 (2):127-150.

FernÁndez-Posse, M ${ }^{\mathrm{a}}$ D; Sánchez-Palencia, F.; Fernández Manzano, J.; Orejas, A. (1994): Estructura social y territorio en la Cultura Castreña prerromana. $1^{\circ}$ Congresso de Arqueologia Peninsular. Actas IV, Trabalhos de Antropologia e Etnologia, XXXIV, 3-4: 191-212.

Gómez Moreno, M. (1904): Sobre arqueología primitiva de la región del Duero. Boletín de la Real Academia de la Historia, XLV: 147-160.

González-Tablas, F. J.(1983): Los Castillejos de Sanchorreja y su incidencia en las culturas del Bronce Final y de la Edad del Hierro en la Meseta Norte. Serie Resúmenes de Tesis Doctorales, Universidad de Salamanca.

GonzÁlez-TABlas, F. J. (1988-87): Transición a la Segunda Edad del Hierro. Actas del Coloquio Internacional sobre la Edad del Hierro en la Meseta Norte, Zephyrvs, XXXIX-XL, Salamanca: 49-57.

González-Tablas, F. J. 1989): Los niveles superiores de Sanchorreja. La Primera Edad del Hierro en el borde meridional de la Meseta. Trabajos de Prehistoria, 46: 117-128.

González-Tablas, F. J. (1990): La necrópolis de "Los Castillejos" de Sanchorreja. Su contexto histórico. Acta Salmanticensia, 69, Salamanca.

González-Tablas, F. J. (2005): Castro de Los Castillejos (Sanchorreja). Cuadernos de Patrimonio Abulense, 6, Institución Gran Duque de Alba, Diputación Provincial de Ávila.

GonzÁlez Tablas, F. J. (2009): Las murallas de Las Cogotas y La Mesa de Miranda. Apuntes a la arquitectura defensiva de los vettones. Zephyrus, LXIV: 63-79. 
González-Tablas, F. J.; Arias González, L; Benito Álvarez, J. M. (1986): Estudio de la relación relieve/ sistema defensivo en los castros abulenses (fines de la Edad del Bronce-Edad del Hierro). Arqueología Espacial, 9: 113-126.

González-Tablas, F. J. y Domínguez Calvo, A. (1995): Cerámicas pintadas postcocción: fósil guía y conjunto cultural. Zephyrvs, XLVIII: 187-198.

GonzÁlez-Tablas, F. J.; Domínguez Calvo, A. (2002): Los Castillejos de Sanchorreja (Ávila): campañas de 1981, 1982 y 1985. Universidad de Salamanca.

GonzÁlez-Tablas, F.J, Fano Martínez, M.A. y Martínez Liquiniano, A. (1991-92): Materiales inéditos de Sanchorreja procedentes de excavaciones clandestinas: un intento de valoración. Zephyrus, XLIVXLV: 301-329

GutiérRez GonZÁlez, J. A. (1986-87): Tipologías defensivas en la cultura castreña de la montaña leonesa. Actas del Coloquio Internacional sobre la Edad del Hierro en la Meseta Norte, Zephyrvs, XXXIXXL: $329-335$

Harbison, P. (1971): Wooden and Stone Chevaux de Frise in Central and Western Europe. Proceedings of the Prehistoric Society, XXXVII: 195-225.

HeRnÁndez SÁnchez, D. (2011): El poblamiento castreño del occidente salmantino. Los vínculos entre el hábitat y el paisaje. Actas del Primer Congreso de Arqueología de Chamartín (Ávila) (J. P. López García, D. Hernández, J. García, eds.), Ediciones de la Ergástula, Madrid: 139-148.

HiLl, J. D. (1995): Ritual and Rubbish in the Iron Age of Wessex. BAR British Series 242, Oxford.

JoRDÁ PARDO, J. F. (1994): Geoarqueología y Arqueometría: algunos resultados de su aplicación al estudio del registro arqueológico de la provincia de Zamora. Numantia, Arqueologia en Castilla y León, 5: 219-235.

López JimÉnez, O. (2005): Paisajes y estructura social en la Protohistoria del área sudoccidental de la Meseta Norte. Bronce Final y Edad del Hierro en la Península Ibérica. Encuentro de Jóvenes Investigadores 2003 (A. Blanco, C. Cancelo, A. Esparza, eds.), Ediciones Universidad de Salamanca: 336-355.

López-Sáez, J. A.; Blanco-González, A.; López-Merino, L.; Ruiz-Zapata, M. B.; Dorado-Valiño, M.; Pérez-Díaz, S.; Valdeolmillos, A.; Burjachs, F. (2009): Landscape and climatic changes during the end of the Late Prehistory in the Amblés Valley (Ávila, central Spain), from 1200 to 400cal BC. Rhythms and causalities of the anthropisation dynamic in Europe between 8500 and $2500 \mathrm{cal}$ BP: Sociocultural and/or climatic assumptions (D. Galop, L. Carroza, M. Magny, G. Gilaine, eds.), Quaternary International, 200: 90-101.

López SÁez, J. A.; López Merino, L.; Pérez Díaz, S. (2008): Los vettones y sus paisajes: paleoambiente y paleoeconomía de los castros de Ávila. Arqueología Vettona. La Meseta Occidental en la Edad del Hierro (J. Álvarez-Sanchís, ed.), Zona Arqueológica, 12, Museo Arqueológico Regional, Alcalá de Henares: $140-152$.

Luengo, J. M. (1961): Castros leoneses. VI Congreso Nacional de Arqueología (Oviedo 1959): 62-70.

Macarro, C. (1999): El primitivo asentamiento de Salmantica: aportaciones al conocimiento de la Cultura del Soto en el valle del Tormes. Memoria de Grado (inédita), Departamento de Prehistoria, Historia Antigua y Arqueología, Universidad de Salamanca.

Magny, M. (1982): Atlantic and Sub-boreal: dampness and dryness? Climatic Change in Later Prehistory (A. Harding, ed.), Edinburgh: 33-43.

Maluquer de Motes, J. (1958a): Excavaciones Arqueológicas en el Cerro del Berrueco (Salamanca). Acta Salmanticensia, XIV-1, Salamanca.

Maluquer de Motes, J. (1958b): El castro de Los Castillejos en Sanchorreja. Ávila-Salamanca.

Maluquer de Motes, J. (1968): Excavaciones Arqueológicas en el castro de "Las Merchanas" (Lumbrales, Salamanca). Pyrenae, 4: 101-128.

Mañanes Pérez, T. (1977): Contribución a la carta arqueológica de la provincia de León. León y su historia. Miscelánea histórica, IV, León: 319-364.

Martín Benito, J. I. y Martín Benito, J. C. (1994): Prehistoria y romanización de la tierra de Ciudad Rodrigo. Ciudad Rodrigo. 
Martín Valls, R. (1971): El castro del Picón de la Mora (Salamanca). Boletín del Seminario de Arte y Arqueología, XXXVII: 125-144.

Martín Valls, R. (1988-87): La Segunda Edad del Hierro: consideraciones sobre su periodización. Actas del Coloquio Internacional sobre la Edad del Hierro en la Meseta Norte, Zephyrvs, XXXIX-XL: 59-86.

Martín Valls, R. (1998): La Edad del Hierro. Historia de Salamanca. I. Prehistoria y Edad Antigua (J. L. Martín, dir), (2 ed.) Centro de Estudios Salmantinos, Salamanca: 123-217.

Martín Valls, R., Benet, N. y Macarro, C.(1991): Arqueología de Salamanca. Del Paleolítico a la Historia (M. Santonja, coord.), Salamanca: 137-163.

Misiego Tejeda, J.C.; Marcos Contreras, G. J.; Martín Carbajo, M.A.; Sanz García F. J.; Villanueva Martín, L. A. (2005): Guaya (Berrocalejo de Aragona, Ávila): reconstrucción de la vida y economía de un poblado en los albores de la Edad del Hierro. Bronce Final y Edad del Hierro en la Península Ibérica (A. Blanco, C. Cancelo, A. Esparza, eds.), Encuentro de Jóvenes Investigadores, Universidad de Salamanca, Salamanca: 207-228.

Misiego Tejeda, J. C.; Marcos Contreras, G. J.; Martín Carbajo, M. A.; Sanz García F. J. (2006): Últimas investigaciones de la Edad del Hierro en la provincia de Zamora: El yacimiento de "La Corona/El Pesadero" en Manganeses de la Polvorosa. Segundo Congreso de Historia de Zamora, Actas I, Instituto de Estudios Zamoranos "Florián de Ocampo", Zamora: 103-141.

Misiego Tejeda, J. C.; Martín Carbajo, M. A.; Marcos Contreras, G. J.; Sanz García, F. J. (1997): Excavaciones arqueológicas en el yacimiento de La Corona/El Pesadero, en Manganeses de la Polvorosa (Zamora), Anuario 1997, Instituto de Estudios Zamoranos Florián de Ocampo, Zamora: 17-41.

Misiego Tejeda, J. C.; Martín Carbajo, M. A.; Sanz García, F. J.; Marcos Contreras, G. J.; Larrén Izquierdo, H. (1998): Arqueología en territorio astur. La Corona/El Pesadero (Zamora). Revista de Arqueología, 208: 24-35.

Misiego Tejeda, J. C.; Pérez Rodríguez, F.; Sanz García, F. J.; Marcos Contreras, G. J.; Martín Carbajo, M. A: (1992): Nuevos datos sobre el grupo castreño del noroeste de Zamora. El "castro de la Luz" (Moveros). Anuario 1992. Instituto de Estudios Zamoranos Florián de Ocampo, Zamora: 55-78.

Misiego Tejeda, J. C.; Sanz García, F. J.; Marcos Contreras, G. J. y Martín Carbajo, M. A. (1999): Excavaciones Arqueológicas en el castro de Sacaojos (Santiago de la Valduerna, León). Numantia. Arqueología en Castilla y León, 7: 43-65.

Muñoz-Sobrino, C.; Ramil-Rego, P.; Gómez Orellana, L; Rodríguez-Guitián, M. (1996): Modificaciones del paisaje vegetal durante el Cuaternario en el NW de la Península Ibérica. Contextualización de las secuencias del SW de Europa. Férvedes, 3: 117-150.

OREJAS, A. (1996): Estructura social y territorio. El impacto romano en la cuenca noroccidental del Duero. Anejos de Archivo Español de Arqueología, XV, Madrid.

PIÑEl (1976): Materiales del poblado de Las Paredejas en el Cerro del Berrueco. Una nueva arracada. Zephyrus, XXVI-XXVII: 351-368.

Quintana López, J.; Cruz Sánchez, P. J. (1996): Del Bronce al Hierro en el centro de la Submeseta Norte (Consideraciones desde el Inventario Arqueológico de Valladolid). Boletín del Seminario de Arte y Arqueología, LXII: 9-78.

Ramil-Rego, P. (1993): Evolución climática e historia de la vegetación durante el Pleistoceno Superior y el Holoceno en las regiones montañosas del Noroeste Ibérico. La evolución del paisaje en las montañas del entorno de los caminos jacobeos. Cambios ambientales y actividad humana (A. Pérez Alberti, L. Guitián Rivera, P. Ramil-Rego, eds), Santiago de Compostela: 25-60.

Ramil-Rego, P.; Gómez Orellana, L.; Muñoz-Sobrino, C.; Rodríguez-Guitián, M. (1996): Valoración de las secuencias polínicas del norte de la península Ibérica para el último ciclo glaciar-interglaciar. Férvedes, 3: 33-116.

Ramil-Rego, P.; Rodríguez-Guití́n, M.; MúÑoz-Sobrino, C. (1998): Sclerophyllous vegetation dynamics in the north of the Iberian peninsula during the last 16,000 years. Global Ecology and Biogeography Letters, 7 (5): 335-351.

Ramírez Ramírez, Mª L. (1999): La casa circular durante la primera Edad del Hierro en el Valle del Duero. Numantia. Arqueología en Castilla y León, 7: 67-94. 
Rodríguez Marcos, J. A.; Marcos Contreras, G. J.; Martín Carbajo, M. A.; Misiego Tejeda, J. C.; Sanz GARCíA, F. J. (1999): Excavaciones arqueológicas en "Las Vegas"(Jabares de los Oteros), un yacimiento arqueológico del 'horizonte Protocogotas I' en la provincia de León. Protección del patrimonio cultural y obras públicas. Actuaciones arqueológicas en la autopista del Camino de Santiago (1994-1997) (J. M. Vidal Encinas, ed.), León: 49-70.

Romero Carnicero, F.; Ramírez Ramírez, Ma L. (1996): La cultura del Soto. Reflexiones sobre los contactos entre el Duero medio y las tierras del sur peninsular durante la Primera Edad del Hierro. Homenaje al Profesor Manuel Fernández-Miranda (M. A. Querol, T. Chapa, eds.), Complutum Extra, 6 (I): 313-326.

Romero, F.; Sanz, C.; Álvarez-SAnchís, J. R. (2008): El primer milenio a.C. en las tierras del interior peninsular. De Iberia a Hispania (F. Gracia, coord.), Ariel, Barcelona: 649-732.

Ruddiman, W.F.; MacIntyre, A. (1981): The north Atlantic Ocean during the last deglaciation. Paleogeography, Paleoclimatology, Paleoecology, 35: 145-214.

Ruiz Entrecanales, R. (2005): Guía Castro de Las Cogotas (Cardeñosa, Ávila). Ávila. Cuadernos de Patrimonio Abulense, Institución Gran Duque de Alba, Diputación de Ávila.

Ruiz Zapatero, G. (2003): Las fortificaciones de la Primera Edad del Hierro en la Europa templada. Chevaux de frise i fortificació en la primera edat del ferro europea (N. Alonso, E. Junyent, A. Lafuente, J. B. López, coords.), Lleida: 13-34.

Ruiz Zapatero, G. y Álvarez-Sanchís, J. R. (1995): Las Cogotas: Oppida and the Roots of Urbanism in the Spanish Meseta. Social complexity and the Development of Towns in Iberia: from the Copper Age to the second century AD. (B. Cunliffe, S. J. Keay, eds.), Proceedings of the British Academy, 86, Londres: 209-236. 